\title{
Comparison and analysis of two forms of harvesting functions in the two-prey and one-predator model
}

\author{
Xinxin Liu, ${ }^{1} 2^{*}$ and Qingdao Huang ${ }^{2}$
}

\section{"Correspondence:}

liuxx78@mail.sysu.edu.cn

'School of Mathematics (Zhuhai),

Sun Yat-sen University, Zhuhai,

China

${ }^{2}$ School of Mathematics, Jilin

University, Changchun, China

\section{然 Springer}

\begin{abstract}
A new way to study the harvested predator-prey system is presented by analyzing the dynamics of two-prey and one-predator model, in which two teams of prey are interacting with one team of predators and the harvesting functions for two prey species takes different forms. Firstly, we make a brief analysis of the dynamics of the two subsystems which include one predator and one prey, respectively. The positivity and boundedness of the solutions are verified. The existence and stability of seven equilibrium points of the three-species model are further studied. Specifically, the global stability analysis of the coexistence equilibrium point is investigated. The problem of maximum sustainable yield and dynamic optimal yield in finite time is studied. Numerical simulations are performed using MATLAB from four aspects: the role of the carrying capacity of prey, the simulation about the model equations around three biologically significant steady states, simulation for the yield problem of model system, and the comparison between the two forms of harvesting functions. We obtain that the new form of harvesting function is more realistic than the traditional form in the given model, which may be a better reflection of the role of human-made disturbance in the development of the biological system.
\end{abstract}

MSC: 34D20; 49M30; 92B05

Keywords: Three species model; Harvesting function; Maximum sustainable yield; Global stability

\section{Introduction}

The interaction between the predator and prey is one of basic relationships among biological species, which becomes one of the hot issues in ecology and biomathematics. The predator-prey model is widely used in renewable resources management [1-5], marine resource conservation [6-8], biological control [9-12], the research about animal infectious diseases [13-15], and so on. Freedman and Wolkowicz [16] firstly put forward a general model

$$
\left\{\begin{array}{l}
\frac{d x}{d t}=x g(x, k)-y \phi(x), \\
\frac{d y}{d t}=y(q(x)-m),
\end{array}\right.
$$

(C) The Author(s) 2019. This article is distributed under the terms of the Creative Commons Attribution 4.0 International License (http://creativecommons.org/licenses/by/4.0/), which permits unrestricted use, distribution, and reproduction in any medium, provided you give appropriate credit to the original author(s) and the source, provide a link to the Creative Commons license, and indicate if changes were made. 
where $\phi(x)$ denotes the predator response function, which reflects the capture ability of the predator to prey. $q(x)$ is the rate of conversion of prey, $g(x, k)$ and $m$ are the growth pattern of prey and the per capita death rate of predator, respectively. The model proposed in this paper is also based on model (1.1).

When it comes to human intervention, the harvesting function is essential and the researching on the dynamics of harvested predator-prey system is necessary, which has been extensively done by a number of researchers [17-20]. When we only harvest the prey species in a predator-prey system, model (1.1) becomes

$$
\left\{\begin{array}{l}
\frac{d x}{d t}=x g(x, k)-y \phi(x)-H(x, E), \\
\frac{d y}{d t}=y(q(x)-m),
\end{array}\right.
$$

where $H(x, E)$ is the harvesting function.

Several types of harvesting function have been widely studied, especially the following three types [21]: (a) Constant harvesting $H(x, E)=h$, where $h$ is a suitable constant; (b) Proportionate harvesting $H(x, E)=q E x$, where $q$ is the catchability coefficient and $E$ is the harvesting effort; and (c) Nonlinear harvesting $H(x, E)=\frac{q E x}{m_{1} E+m_{2} x}$, where $m_{1}, m_{2}$ are suitable positive constants.

Xiao and Jennings [22] systematically studied the dynamical properties of the ratiodependent predator-prey model with nonzero constant harvesting. They have shown that the harvested system can exhibit far richer dynamics compared to the model with no harvesting, such as numerous kinds of bifurcations. Das et al. [19] considered a simple two species predator-prey model in which both species are harvested in proportion. The dynamical behavior of the exploited system has been examined and the optimal harvesting policy has been studied. Li et al. [21] considered a bioeconomic predator-prey model with Holling type II functional response and nonlinear prey harvesting. The effect of economic profit on the proposed model has been analyzed by viewing it as a bifurcation parameter.

In these traditional harvested predator-prey models, the harvesting function appears as a separate item. Human's harvesting and the internal reproduction of a biological system itself take place simultaneously. The change in prey population density is indicated directly as the difference value between the number of growth and the number of prey captured by predator and human. Considering the impact of harvesting on the system, we propose that the changes in population density next time should not include the part harvested by the human. We are likely to overlook the point that the part harvested by the human no longer affects the reproduction of the species group; in other words, the part harvested by the human has no concern with the whole, and they can not be captured by predator species again. The relevant schematic is presented in Figure 1.

Some authors considered a prey-predator system with a proportion refuge [23-26]. Lv et al. [23] studied the model incorporating a refuge protecting $m_{1} x$ of the prey, where $m_{1}$ $\left(m_{1} \in[0,1]\right)$ is a constant, which leaves $\left(1-m_{1}\right) x$ of the prey available to the predator. Ma et al. [26] proposed a patchy predator-prey model with one patch as refuge and the other as open habitat and incorporated prey refuge $x_{R}$ in the considered model explicitly. Here, we regard the harvesting term $H(x, E)$ as a special part which is no longer related to the development of the predator-prey system. To give a more in-depth comparison and analysis, we put forward a new form of harvested predator-prey system, in which two 


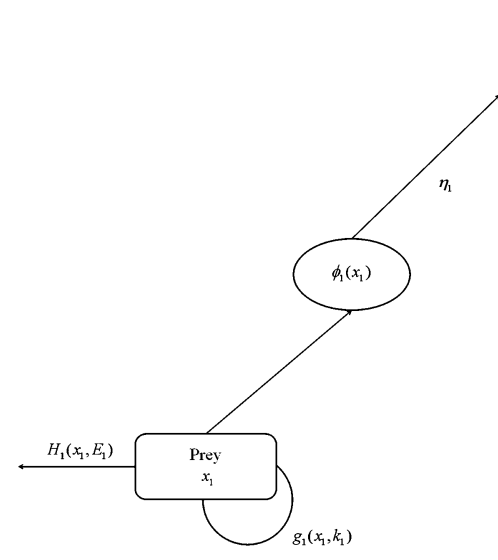

(a)

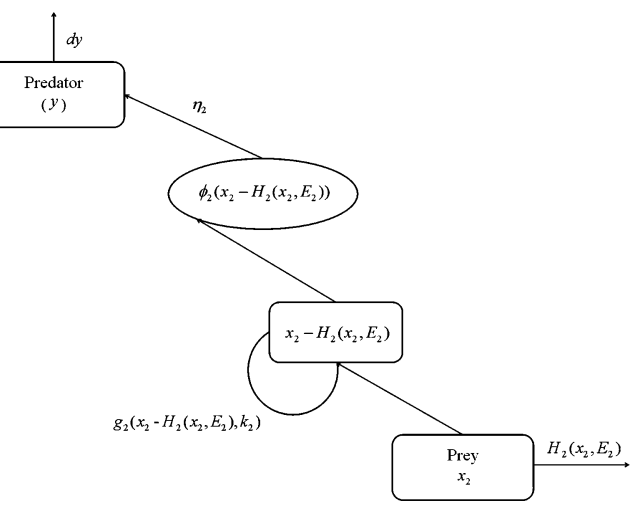

(b)

Figure 1 The sketch map of the two forms of harvesting functions. (a) A harvested predator-prey model with traditional form of harvesting function. (b) A harvested predator-prey model with a new form of harvesting function, where $\phi_{1}$ and $\phi_{2}$ denote the predator response function of two prey species, respectively. $\eta_{1}$ and $\eta_{2}$ are the rate of conversion of prey. $g_{1}$ and $g_{2}$ are the growth pattern of two prey species. $m$ is the per capita death rate of predator

teams of prey interacting with one team of predators and the harvesting function for two prey species takes different forms:

$$
\left\{\begin{aligned}
\frac{d x_{1}}{d t}= & x_{1} g_{1}\left(x_{1}, k_{1}\right)-y \phi_{1}\left(x_{1}\right)-H_{1}\left(x_{1}, E_{1}\right)-\sigma\left(x_{1}, x_{2}-H_{2}\left(x_{2}, E_{2}\right)\right), \\
\frac{d x_{2}}{d t}= & \left(x_{2}-H_{2}\left(x_{2}, E_{2}\right)\right) g_{2}\left(x_{2}-H_{2}\left(x_{2}, E_{2}\right), k_{2}\right)-y \phi_{2}\left(x_{2}-H_{2}\left(x_{2}, E_{2}\right)\right) \\
& -\sigma\left(x_{1}, x_{2}-H_{2}\left(x_{2}, E_{2}\right)\right), \\
\frac{d y}{d t}= & \eta_{1} \phi_{1}\left(x_{1}\right) y+\eta_{2} \phi_{2}\left(x_{2}-H_{2}\left(x_{2}, E_{2}\right)\right) y-m y .
\end{aligned}\right.
$$

In this model, the harvesting function for the first prey $x_{1}$ adopts the traditional form and the other harvesting function for the second prey $x_{2}$ takes the new form we proposed, in which the number of species at the next moment is the change of the part which is not harvested by humans. Further, the harvesting of the prey also affects the growth of the predator in that the prey harvested by humans can not be captured by predator again. $\sigma$ represents interspecific competition between the two prey species. Researching the dynamics of predator-prey system (1.3) is the focus of this paper. And this kind of model is analyzed in detail through a concrete example.

This paper is organized as follows. The mathematical model is formulated in Sect. 2. In Sect. 3, for underlining the importance of the two different systems before combining the two harvesting forms into one model, we make a brief analysis of the dynamics of the two subsystems, in which prey $x_{1}$ or $x_{2}$ does not exist. The analyses of positivity and boundedness of the solutions are given in Sect. 4. In Sect. 5, we investigate the existence and local stability of the equilibrium points of the system in the closed first quadrant. What is more, global stability analysis about the interior equilibrium point is given. The problem of maximum sustainable yield and dynamic optimal yield in finite time are studied in Sect. 6. In Sect. 7, we perform the numerical simulations using MATLAB from four aspects: investigating the role of the carrying capacity of prey, simulating the model equations around three equilibrium points, simulation for the yield problem of the model sys- 
tem, and making a more in-depth comparison and analysis between the two harvesting functions. Discussion and concluding remarks are presented in Sect. 8.

\section{Mathematical model}

In this paper, in order to draw a precise comparison, based on the model presented in [27], we make two prey species have the same growth function and functional response of the predator, in addition, consider the two-prey one-predator system with proportionate harvesting, then (1.3) takes the form

$$
\left\{\begin{aligned}
\frac{d x_{1}}{d t}= & r_{1} x_{1}\left(1-\frac{x_{1}}{k_{1}}\right)-\beta_{1} x_{1} y-q_{1} E_{1} x_{1}-\sigma x_{1}\left(x_{2}-q_{2} E_{2} x_{2}\right) \\
\triangleq & x_{1} f_{1}\left(x_{1}, x_{2}, y, E_{1}, E_{2}\right), \\
\frac{d x_{2}}{d t}= & r_{2}\left(x_{2}-q_{2} E_{2} x_{2}\right)\left(1-\frac{x_{2}-q_{2} E_{2} x_{2}}{k_{2}}\right)-\beta_{2}\left(x_{2}-q_{2} E_{2} x_{2}\right) y \\
& \quad-\sigma x_{1}\left(x_{2}-q_{2} E_{2} x_{2}\right) \triangleq\left(1-q_{2} E_{2}\right) x_{2} f_{2}\left(x_{1}, x_{2}, y, E_{2}\right), \\
\frac{d y}{d t}= & \eta_{1} \beta_{1} x_{1} y+\eta_{2} \beta_{2}\left(x_{2}-q_{2} E_{2} x_{2}\right) y-m y \triangleq y g\left(x_{1}, x_{2}, E_{2}\right),
\end{aligned}\right.
$$

here

$$
\left\{\begin{array}{l}
f_{1}\left(x_{1}, x_{2}, y, E_{1}, E_{2}\right)=r_{1}\left(1-\frac{x_{1}}{k_{1}}\right)-\beta_{1} y-q_{1} E_{1}-\sigma x_{2}\left(1-q_{2} E_{2}\right), \\
f_{2}\left(x_{1}, x_{2}, y, E_{2}\right)=r_{2}\left[1-\frac{\left(1-q_{2} E_{2}\right) x_{2}}{k_{2}}\right]-\beta_{2} y-\sigma x_{1}, \\
g\left(x_{1}, x_{2}, E_{2}\right)=\eta_{1} \beta_{1} x_{1}+\eta_{2} \beta_{2}\left(1-q_{2} E_{2}\right) x_{2}-m .
\end{array}\right.
$$

The following assumptions are taken into account for system (2.1):

1. Assume that the three species are subject to the positive initial conditions.

2. The growth pattern of two prey species is simulated with logistic equation in the absence of predator and harvesting, of which the parameter $r_{i}$ represents the intrinsic growth rate of prey $x_{i}(i=1,2), k_{i}$ is the carrying capacity of prey $x_{i}$.

3. $d$ is the per capita death rate of the predator $y$.

4. For simplicity, the feeding rate of the predator species is assumed to increase linearly with prey density $[18,27]$. The predator captures prey $x_{i}(i=1,2)$ at a rate proportional to prey abundance with rate coefficient $\beta_{i}$, and this contributes to an increase in the predator population with a conversion rate of $\eta_{i}$ [28]. Since $\eta_{i}=1$ represents a biomass of foraged prey can be completely converted to predator without any loss $[29,30]$, which could not possibly happen in real life. Therefore we assumed $0<\eta_{1}<1$ and $0<\eta_{2}<1$ [31] in this paper.

5. The constant $E_{i}$ is the harvesting effort of prey $x_{i}(i=1,2) . q_{i}$ is the catchability coefficient of prey $x_{i}$. It is biologically meaningful to consider the case when $1-q_{2} E_{2}>0$. Further, the predator population is not harvested.

6. $r_{i}, k_{i}, \beta_{i}, \eta_{i}, \sigma, m$ are positive rate constants.

\section{The analysis of two subsystems}

Firstly, we briefly analyze the two different systems before combining the two harvesting forms into one model. 


\subsection{In the absence of prey $x_{2}$}

Model (2.1) in the absence of prey $x_{2}$ is equivalent to the predator-prey model with traditional harvesting function given by

$$
\left\{\begin{array}{l}
\frac{d x_{1}}{d t}=r_{1} x_{1}\left(1-\frac{x_{1}}{k_{1}}\right)-\beta_{1} x_{1} y-q_{1} E_{1} x_{1} \\
\frac{d y}{d t}=\eta_{1} \beta_{1} x_{1} y-m y
\end{array}\right.
$$

subject to the positive initial conditions $x_{1}(0)>0, y(0)>0$.

System (3.1) has a unique interior equilibrium point $S_{1}^{*}\left(\tilde{x}_{1}, \tilde{y}\right)$ where

$$
\tilde{x}_{1}=\frac{m}{\eta_{1} \beta_{1}}, \quad \tilde{y}=\frac{1}{\beta_{1}}\left[r_{1}\left(1-\frac{d}{\eta_{1} \beta_{1} k_{1}}\right)-q_{1} E_{1}\right] .
$$

We can easily prove that $S_{1}^{*}\left(\tilde{x}_{1}, \tilde{y}\right)$ is locally as well as globally stable if $E_{1}<\frac{r_{1}}{q_{1}}\left(1-\frac{m}{\beta_{1} \eta_{1} k_{1}}\right)$, which is the condition of its existence.

\subsection{In the absence of prey $x_{1}$}

Model (2.1) in the absence of prey $x_{1}$ is equivalent to the predator-prey model with a new form harvesting function given by

$$
\left\{\begin{array}{l}
\frac{d x_{2}}{d t}=r_{2}\left(1-q_{2} E_{2}\right) x_{2}\left[1-\frac{\left(1-q_{2} E_{2}\right) x_{2}}{k_{2}}\right]-\beta_{2}\left(1-q_{2} E_{2}\right) x_{2} y, \\
\frac{d y}{d t}=\eta_{2} \beta_{2}\left(1-q_{2} E_{2}\right) x_{2} y-m y
\end{array}\right.
$$

subject to the positive initial conditions $x_{2}(0)>0, y(0)>0$.

System (3.3) has a unique interior equilibrium point $S_{2}^{*}\left(\bar{x}_{2}, \bar{y}\right)$ where

$$
\bar{x}_{2}=\frac{m}{\eta_{2} \beta_{2}\left(1-q_{2} E_{2}\right)}, \quad \bar{y}=\frac{r_{2}}{\beta_{2}}\left(1-\frac{m}{\eta_{2} \beta_{2} k_{2}}\right) .
$$

Similarly, $S_{2}^{*}\left(\bar{x}_{2}, \bar{y}\right)$ is locally as well as globally stable if $m<\eta_{2} \beta_{2} k_{2}$ and $E_{2}<1 / q_{2}$, which are also the conditions of its existence. Further, after rearranging the form of differential equation (3.3), system (3.3) becomes of the following form:

$$
\left\{\begin{array}{l}
\frac{d x_{2}}{d t}=r_{2} x_{2}\left(1-\frac{x_{2}}{k_{2}}\right)-\beta_{2} x_{2} y-\delta_{1}\left(x_{2}, y, E_{2}\right), \\
\frac{d y}{d t}=\eta_{2} \beta_{2} x_{2} y-m y-\delta_{2}\left(x_{2}, y, E_{2}\right)
\end{array}\right.
$$

where

$$
\begin{aligned}
& \delta_{1}\left(x_{2}, y, E_{2}\right)=q_{2} E_{2} x_{2}\left[r_{2}\left(1-\frac{2 x_{2}-q_{2} E_{2} x_{2}}{k_{2}}\right)-\beta_{2} y\right], \\
& \delta_{2}\left(x_{2}, y, E_{2}\right)=\eta_{2} \beta_{2} q_{2} E_{2} x_{2} y .
\end{aligned}
$$

Compared with the form of model (3.1), the terms $\delta_{1}$ and $\delta_{2}$ may be the correction terms for the traditional harvesting function given in (3.1) that interpret the schematic presented in Figure 1 better. From (3.5), the new form of harvesting function refines the effects of human intervention, which shows that harvesting prey affects not only the growth of the prey population, but also the growth of the predator population. 
In addition, observing the composition of the two interior equilibrium points

$$
\begin{aligned}
& S_{1}^{*}\left(\tilde{x}_{1}, \tilde{y}\right)=\left(\frac{m}{\eta_{1} \beta_{1}}, \frac{1}{\beta_{1}}\left[r_{1}\left(1-\frac{m}{\eta_{1} \beta_{1} k_{1}}\right)-q_{1} E_{1}\right]\right), \\
& S_{2}^{*}\left(\bar{x}_{2}, \bar{y}\right)=\left(\frac{m}{\eta_{2} \beta_{2}\left(1-q_{2} E_{2}\right)}, \frac{r_{2}}{\beta_{2}}\left(1-\frac{m}{\eta_{2} \beta_{2} k_{2}}\right)\right),
\end{aligned}
$$

we know that only $\bar{x}_{2}$ has connection with the harvesting effort $E_{2}$ in the form of $S_{2}^{*}$. The opposite situation occurs in $S_{1}^{*}$. As human harvesting is considered, the harvesting value $E_{i}$ may influence the quantity of prey $x_{i}(i=1,2)$ in equilibrium point directly, then the form of $S_{2}^{*}$ is easier to be understood than the form of $S_{1}^{*}$ in biological terms. The further comparison and analysis of two forms of harvesting functions are carried out by numerical simulation in Sect. 7.

\section{Positivity and boundedness of the solutions}

In this section, we study the positivity and boundedness of the solutions of system (2.1).

Theorem 1 All the solutions of system (2.1) with the positive initial conditions are positive for all $t \geq 0$ and uniformly bounded.

Proof From system (2.1) with positive initial conditions, we have

$$
\begin{aligned}
x_{1}(t) & =x_{1}(0) \exp \left\{\int_{0}^{t}\left[r_{1} x_{1}(s)\left(1-\frac{x_{1}(s)}{k_{1}}\right)-\beta_{1} x_{1}(s) y(s)-s_{1} x_{1}(s)-\sigma s_{2} x_{1}(s) x_{2}(s)\right] d s\right\} \\
& >0, \\
x_{2}(t) & =x_{2}(0) \exp \left\{\int_{0}^{t}\left[r_{2} s_{2} x_{2}(s)\left(1-\frac{s_{2} x_{2}(s)}{k_{2}}\right)-\beta_{2} s_{2} x_{2}(s) y(s)-\sigma s_{2} x_{1}(s) x_{2}(s)\right] d s\right\} \\
& >0, \\
y(t) & =y(0) \exp \left\{\int_{0}^{t}\left[\eta_{1} \beta_{1} x_{1}(s) y(s)+\eta_{2} \beta_{2} s_{2} x_{2}(s) y(s)-m y(s)\right] d s\right\}>0,
\end{aligned}
$$

where $s_{1}=q_{1} E_{1}, s_{2}=1-q_{2} E_{2}$.

Now, we define the function $\Omega(t)=\eta_{1} x_{1}+\eta_{2} x_{2}+y$.

Then differentiating $\Omega$ with respect to $t$ and using the equations in system (2.1), we have

$$
\begin{aligned}
\frac{d \Omega(t)}{d t} & =\eta_{1} \frac{d x_{1}}{d t}+\eta_{2} \frac{d x_{2}}{d t}+\frac{d y}{d t} \\
& =\eta_{1} r_{1} x_{1}\left(1-x_{1} / k_{1}\right)-\eta_{1} s_{1} x_{1}-\left(\eta_{1}+\eta_{2}\right) \sigma s_{2} x_{1} x_{2}+\eta_{2} r_{2} s_{2} x_{2}\left(1-s_{2} x_{2} / k_{2}\right)-m y .
\end{aligned}
$$

Therefore,

$$
\begin{aligned}
\frac{d \Omega}{d t}+m \Omega= & -\frac{\eta_{1} r_{1}}{k_{1}}\left[x_{1}-\frac{k_{1}\left(r_{1}-s_{1}+m\right)}{2 r_{1}}\right]^{2}+\frac{k_{1} \eta_{1}\left(r_{1}-s_{1}+m\right)^{2}}{4 r_{1}} \\
& -\frac{\eta_{2} r_{2} s_{2}^{2}}{k_{2}}\left[x_{2}-\frac{k_{2}\left(r_{2} s_{2}+m\right)}{2 r_{2} s_{2}^{2}}\right]^{2}+\frac{k_{2} \eta_{2}\left(r_{2} s_{2}+m\right)^{2}}{4 r_{2} s_{2}^{2}} \\
& -\left(\eta_{1}+\eta_{2}\right) \sigma s_{2} x_{1} x_{2}
\end{aligned}
$$




$$
\begin{aligned}
& \leq \frac{k_{1} \eta_{1}\left(r_{1}-s_{1}+m\right)^{2}}{4 r_{1}}+\frac{k_{2} \eta_{2}\left(r_{2} s_{2}+m\right)^{2}}{4 r_{2} s_{2}^{2}} \\
& \triangleq L>0 .
\end{aligned}
$$

The right-hand side of the above inequality is bounded for $\left(x_{1}, x_{2}, y\right) \in \mathbb{R}_{+}^{3}$.

Applying the theory of differential inequality, we have

$$
0<\Omega(t) \leq \frac{L}{m}\left[1-e^{-m t}\right]+\Omega(0) e^{-m t} .
$$

As $t \rightarrow \infty$, we can see that the limit of the right-hand side of (4.1) is $L / m$. Hence, by the definition of $\Omega(t)$, we can imply that all the solutions of system (2.1) are bounded in the interior of $R_{+}^{3}$.

The proof is complete.

\section{Existence and stability of equilibria}

In this section we investigate the existence and stability of the equilibrium points of system (2.1) in the closed first quadrant.

\subsection{Existence of equilibria}

Model system (2.1) possesses seven equilibrium points including one trivial, two axial, three boundary, and one interior equilibrium point.

1. The trivial equilibrium point $S_{0}=(0,0,0)$ exists irrespective of any parametric restriction.

2. Two axial equilibrium points of model (2.1) are given by $S_{1}\left(0, \hat{x}_{2}, 0\right)$ and $S_{2}\left(\breve{x}_{1}, 0,0\right)$, where

$$
\hat{x}_{2}=\frac{k_{2}}{1-q_{2} E_{2}}, \quad \breve{x}_{1}=k_{1}\left(1-\frac{q_{1} E_{1}}{r_{1}}\right) .
$$

Clearly, $S_{1}$ exists when the assumption $E_{2}<1 / q_{2}$ holds, the feasibility condition for $S_{2}$ is $E_{1}<r_{1} / q_{1}$, which is $E_{1}<\operatorname{BTP}_{x_{1}}$. The ratio $\left(r_{1} / q_{1}\right)$ of the biotic potential to the catchability coefficient $\left(q_{1}\right)$ is known as the biotechnical productivity (BTP) of prey $x_{1}$ species [32].

3. In the absence of prey $x_{1}$ the boundary equilibrium point in the $x_{2} y$-plane is given by $S_{3}\left(0, \bar{x}_{2}, \bar{y}\right)$, where $\bar{x}_{2}$ and $\bar{y}$ are given in (3.4). The feasible condition for $S_{3}$ is $m<\eta_{2} \beta_{2} k_{2}$.

4. In the absence of prey $x_{2}$ the boundary equilibrium point in the $x_{1} y$-plane is given by $S_{4}\left(\tilde{x}_{1}, 0, \tilde{y}\right)$, where $\tilde{x}_{1}$ and $\tilde{y}$ are given in (3.2). The feasible condition for $S_{4}$ is $E_{1}<\frac{r_{1}}{q_{1}}\left(1-\frac{m}{\eta_{1} \beta_{1} k_{1}}\right)$.

5. The predator-free boundary equilibrium point in the $x_{1} x_{2}$-plane is given by $S_{5}\left(\check{x}_{1}, \check{x}_{2}, 0\right)$, where

$$
\check{x}_{1}=\frac{r_{2} k_{1}\left(k_{2} \sigma+q_{1} E_{1}-r_{1}\right)}{\sigma^{2} k_{1} k_{2}-r_{1} r_{2}}, \quad \check{x}_{2}=\frac{r_{1}\left(k_{1}-\check{x}_{1}\right)-q_{1} E_{1} k_{1}}{\sigma k_{1}\left(1-q_{2} E_{2}\right)} .
$$

The feasible existence of $S_{5}$ demands the parametric restriction

$$
\left(k_{2} \sigma+q_{1} E_{1}-r_{1}\right)\left(\sigma^{2} k_{1} k_{2}-r_{1} r_{2}\right)>0, \quad r_{1}\left(k_{1}-\check{x}_{1}\right)-q_{1} E_{1} k_{1}>0 .
$$


6. Apart from the axial and boundary equilibrium points, there is a unique interior equilibrium point $S^{*}\left(x_{1}^{*}, x_{2}^{*}, y^{*}\right)$ with

$$
\begin{aligned}
& x_{1}^{*}=\frac{m v_{2}+\eta_{2} \beta_{2}\left[-r_{2} \beta_{1}+\beta_{2}\left(r_{1}-q_{1} E_{1}\right)\right]}{\eta_{2} \beta_{2} v_{1}+\eta_{1} \beta_{1} v_{2}}, \quad x_{2}^{*}=\frac{m-\eta_{1} \beta_{1} x_{1}^{*}}{\eta_{2} \beta_{2}\left(1-q_{2} E_{2}\right)}, \\
& y^{*}=\frac{1}{\beta_{1}}\left[r_{1}\left(1-\frac{x_{1}^{*}}{k_{1}}\right)-q_{1} E_{1}-\sigma x_{2}^{*}\left(1-q_{2} E_{2}\right)\right],
\end{aligned}
$$

where $v_{1}=\frac{\beta_{2} r_{1}}{k_{1}}-\sigma \beta_{1}, v_{2}=\frac{\beta_{1} r_{2}}{k_{2}}-\sigma \beta_{2}$.

The interior equilibrium point is feasible when each term of $S^{*}\left(x_{1}^{*}, x_{2}^{*}, y^{*}\right)$ is greater than zero. Due to the complexity of the calculation, we carry out detailed analysis in Sect. 7.2.

\subsection{Local stability of equilibria}

Here we provide the local stability conditions for feasible equilibrium points of system (2.1) based on the standard linearization technique, and then use the famous RouthHurwitz criterion [33] to determine the properties of eigenvalues of the matrix associated with the linearized version. If $y=0$, system (2.1) becomes a two-species competitive model, in which we are not interested. In this section, we mainly study the following steady states: $S_{0}(0,0,0), S_{3}\left(0, \bar{x}_{2}, \bar{y}\right), S_{4}\left(\tilde{x}_{1}, 0, \tilde{y}\right)$, and $S^{*}\left(x_{1}^{*}, x_{2}^{*}, y^{*}\right)$.

The Jacobian matrix of system $(2.1)$ at any point $\left(x_{1}, x_{2}, y\right)$ takes the form

$$
J_{\left(x_{1}, x_{2}, y\right)}=\left[\begin{array}{lll}
\zeta_{11} & \zeta_{12} & \zeta_{13} \\
\zeta_{21} & \zeta_{22} & \zeta_{23} \\
\zeta_{31} & \zeta_{32} & \zeta_{33}
\end{array}\right],
$$

where

$$
\begin{aligned}
& \zeta_{11}=-q_{1} E_{1}-\beta_{1} y-r_{1}\left(\frac{2 x_{1}}{k_{1}}-1\right)-\sigma\left(1-q_{2} E_{2}\right) x_{2}, \quad \zeta_{12}=-\sigma x_{1}\left(1-q_{2} E_{2}\right), \\
& \zeta_{13}=-\beta_{1} x_{1}, \quad \zeta_{21}=-\sigma x_{2}\left(1-q_{2} E_{2}\right), \quad \zeta_{23}=-\beta_{2} x_{2}\left(1-q_{2} E_{2}\right), \\
& \zeta_{22}=-\left(1-q_{2} E_{2}\right)\left[\frac{2 r_{2} x_{2}\left(1-q_{2} E_{2}\right)}{k_{2}}+\beta_{2} y+\sigma x_{1}-r_{2}\right], \\
& \zeta_{31}=\beta_{1} \eta_{1} y, \quad \zeta_{32}=\beta_{2} \eta_{2} y\left(1-q_{2} E_{2}\right), \quad \zeta_{33}=\beta_{1} \eta_{1} x_{1}-m+\beta_{2} \eta_{2}\left(1-q_{2} E_{2}\right) x_{2} .
\end{aligned}
$$

\subsubsection{Stability of $S_{0}=(0,0,0)$}

The eigenvalues of the Jacobian $J\left(S_{0}\right)$ evaluated at the trivial equilibrium point $S_{0}=(0,0,0)$ are $\lambda_{1}=r_{1}-q_{1} E_{1}, \lambda_{2}=r_{2}\left(1-q_{2} E_{2}\right)>0$, and $\lambda_{3}=-m<0$. Hence $S_{0}$ is a saddle point with $\operatorname{dim} W^{s}\left(S_{0}\right)=2$ and $\operatorname{dim} W^{u}\left(S_{0}\right)=1$ if condition (I) $E_{1}>\mathrm{BTP}_{x_{1}}$ is satisfied and $S_{0}$ is a saddle point with $\operatorname{dim} W^{s}\left(S_{0}\right)=1$ and $\operatorname{dim} W^{u}\left(S_{0}\right)=2$ if condition (I) is violated, where $\operatorname{dim} W^{s}$ and $\operatorname{dim} W^{u}$ denote the dimensions of stable and unstable subspaces, respectively.

\subsubsection{Stability of $S_{3}=\left(0, \bar{x}_{2}, \bar{y}\right)$}

One of the eigenvalues of $J\left(S_{3}\right)$ is given by

$$
\bar{\lambda}_{1}=r_{1}-q_{1} E_{1}+\frac{\beta_{1} r_{2}\left(m-\beta_{2} \eta_{2} k_{2}\right)}{\beta_{2}^{2} \eta_{2} k_{2}}-\frac{m \sigma}{\beta_{2} \eta_{2}},
$$


and the other eigenvalues $\bar{\lambda}_{ \pm}$are determined by the quadratic equation (see Appendix 1). Based on the existence condition of $S_{3}$, we have

$$
\operatorname{Tr}\left[\bar{J}_{S_{3}}\right]=\frac{m r_{2}\left(q_{2} E_{2}-1\right)}{\beta_{2} \eta_{2} k_{2}}<0, \quad \bar{\lambda}_{+} \bar{\lambda}_{-}=\operatorname{Det} \frac{m r_{2}\left(m-\beta_{2} \eta_{2} k_{2}\right)\left(q_{2} E_{2}-1\right)}{\eta_{2} \beta_{2} k_{2}}>0 .
$$

Then we have $S_{3}$ is locally asymptotically stable if the condition

$$
\text { (II) } \quad E_{1}>\frac{1}{q_{1}}\left[r_{1}+\frac{\beta_{1} r_{2}\left(m-\beta_{2} \eta_{2} k_{2}\right)}{\beta_{2}^{2} \eta_{2} k_{2}}-\frac{m \sigma}{\beta_{2} \eta_{2}}\right] \quad\left(=\bar{E}_{1}\right)
$$

is satisfied. Otherwise, $S_{3}$ is a saddle point with $\operatorname{dim} W^{s}\left(S_{3}\right)=2$ and $\operatorname{dim} W^{u}\left(S_{3}\right)=1$. Ecologically, we can say that in this case the coexistence of prey $x_{2}$ and the predator is possible if the harvesting effort of prey $x_{1}$ exceeds the critical value $\bar{E}_{1}$.

\subsubsection{Stability of $S_{4}=\left(\tilde{x}_{1}, 0, \tilde{y}\right)$}

The characteristic equation for the variational matrix $J\left(S_{4}\right)$ is $\lambda^{3}+\varphi_{1} \lambda^{2}+\varphi_{2} \lambda+\varphi_{3}=0$ (see Appendix 2).

According to the Routh-Hurwitz criterion, $S_{4}$ is locally asymptotically stable if $\varphi_{1}>0$, $\varphi_{3}>0$, and $\varphi_{1} \varphi_{2}-\varphi_{3}>0$.

\subsubsection{Stability of $S^{*}=\left(x_{1}^{*}, x_{2}^{*}, y^{*}\right)$}

The characteristic equation associated with the matrix $J\left(S^{*}\right)$ is given by $\lambda^{3}+\xi_{1} \lambda^{2}+\xi_{2} \lambda+$ $\xi_{3}=0$ (see Appendix 3).

According to the Routh-Hurwitz criterion, the interior equilibrium point $S^{*}$ is locally asymptotically stable if $\xi_{1}>0, \xi_{3}>0$, and $\xi_{1} \xi_{2}-\xi_{3}>0$. It is quite difficult to find explicit parametric restriction for the local asymptotic stability of $S^{*}$, so we discuss it for some specific choice of system parameters in Sect. 7.2.

\subsection{Global stability analysis}

In this section, we consider the global asymptotic stability for the interior equilibrium point $S^{*}$ with the help of Lyapunov functional construction method [34].

Theorem 2 The positive interior equilibrium point $S^{*}\left(x_{1}^{*}, x_{2}^{*}, y^{*}\right)$ is globally asymptotically stable if $4 \eta_{1} \eta_{2} r_{1} r_{2}>\sigma^{2} k_{1} k_{2}$.

Proof Obviously, $\left(x_{1}^{*}, x_{2}^{*}, y^{*}\right)$ satisfies the equalities

$$
\left\{\begin{array}{l}
r_{1}\left(1-\frac{x_{1}^{*}}{k_{1}}\right)-\beta_{1} y^{*}-q_{1} E_{1}-\sigma x_{2}^{*}\left(1-q_{2} E_{2}\right)=0, \\
r_{2}\left[1-\frac{\left(1-q_{2} E_{2}\right) x_{2}^{*}}{k_{2}}\right]-\beta_{2} y^{*}-\sigma x_{1}^{*}=0, \\
\eta_{1} \beta_{1} x_{1}^{*}+\eta_{2} \beta_{2}\left(1-q_{2} E_{2}\right) x_{2}^{*}-m=0
\end{array}\right.
$$

which are equivalent to

$$
\left\{\begin{array}{l}
r_{1}=q_{1} E_{1}+\beta_{1} y^{*}+\frac{r_{1}}{k_{1}} x_{1}^{*}+\sigma x_{2}^{*}\left(1-q_{2} E_{2}\right), \\
r_{2}=\beta_{2} y^{*}+\frac{r_{2}}{k_{2}}\left(1-q_{2} E_{2}\right) x_{2}^{*}+\sigma x_{1}^{*}, \\
m=\eta_{1} \beta_{1} x_{1}^{*}+\eta_{2} \beta_{2}\left(1-q_{2} E_{2}\right) x_{2}^{*} .
\end{array}\right.
$$


Now we show the global stability of interior equilibrium point $S^{*}$ by constructing the Lyapunov function [35], $V\left(x_{1}, x_{2}, y\right): \mathbb{R}_{+}^{3} \rightarrow \mathbb{R}$, s.t.

$$
V\left(x_{1}, x_{2}, y\right)=V_{1}\left(x_{1}, x_{2}, y\right)+V_{2}\left(x_{1}, x_{2}, y\right)+V_{3}\left(x_{1}, x_{2}, y\right),
$$

where $V_{1}\left(x_{1}, x_{2}, y\right)=\eta_{1}\left(x_{1}-x_{1}^{*}-x_{1}^{*} \ln \frac{x_{1}}{x_{1}^{*}}\right), V_{2}\left(x_{1}, x_{2}, y\right)=\eta_{2}\left(x_{2}-x_{2}^{*}-x_{2}^{*} \ln \frac{x_{2}}{x_{2}^{*}}\right), V_{3}\left(x_{1}, x_{2}, y\right)=$ $y-y^{*}-y^{*} \ln \frac{y}{y^{*}}$.

From (5.8), we have

$$
\frac{\partial V\left(x_{1}, x_{2}, y\right)}{\partial x_{i}}=\eta_{i}\left(1-\frac{x_{i}^{*}}{x_{i}}\right) \quad(i=1,2), \quad \frac{\partial V\left(x_{1}, x_{2}, y\right)}{\partial y}=1-\frac{y^{*}}{y}
$$

which shows that the positive equilibrium $\left(x_{1}^{*}, x_{2}^{*}, y^{*}\right)$ is the only extremum of the function $V\left(x_{1}, x_{2}, y\right)$ in the positive quadrant [36]. Then we can easily verify that

$$
\begin{aligned}
& \lim _{x_{1} \rightarrow 0} V\left(x_{1}, x_{2}, y\right)=\lim _{x_{2} \rightarrow 0} V\left(x_{1}, x_{2}, y\right)=\lim _{y \rightarrow 0} V\left(x_{1}, x_{2}, y\right)=+\infty, \\
& \lim _{x_{1} \rightarrow+\infty} V\left(x_{1}, x_{2}, y\right)=\lim _{x_{2} \rightarrow+\infty} V\left(x_{1}, x_{2}, y\right)=\lim _{y \rightarrow+\infty} V\left(x_{1}, x_{2}, y\right)=+\infty .
\end{aligned}
$$

Combining (5.9) and (5.10), we observe that the positive equilibrium is the global minimum. Further, it can be verified that the function $V\left(x_{1}, x_{2}, y\right)$ is zero at $\left(x_{1}^{*}, x_{2}^{*}, y^{*}\right)$. Then we have $V\left(x_{1}, x_{2}, y\right)>V\left(x_{1}^{*}, x_{2}^{*}, y^{*}\right)=0$ for all $x_{1}, x_{2}, y>0$.

The time derivative of $V_{1}$ along the solution of (2.1) is

$$
\frac{d V_{1}}{d t}=\eta_{1}\left(x_{1}-x_{1}^{*}\right)\left[r_{1}\left(1-\frac{x_{1}}{k_{1}}\right)-\beta_{1} y-q_{1} E_{1}-\sigma x_{2}\left(1-q_{2} E_{2}\right)\right] .
$$

After some simplifications and with the help of the first equation of (5.7), (5.11) takes the following form:

$$
\begin{aligned}
\frac{d V_{1}}{d t}= & -\frac{\eta_{1} r_{1}}{k_{1}}\left(x_{1}-x_{1}^{*}\right)^{2}-\eta_{1} \beta_{1}\left(x_{1}-x_{1}^{*}\right)\left(y-y^{*}\right) \\
& -\sigma \eta_{1}\left(1-q_{2} E_{2}\right)\left(x_{1}-x_{1}^{*}\right)\left(x_{2}-x_{2}^{*}\right) .
\end{aligned}
$$

Similarly, we have

$$
\begin{aligned}
\frac{d V_{2}}{d t}= & -\frac{\eta_{2} r_{2}\left(1-q_{2} E_{2}\right)^{2}\left(x_{2}-x_{2}^{*}\right)^{2}}{k_{2}}-\eta_{2} \beta_{2}\left(1-q_{2} E_{2}\right)\left(x_{2}-x_{2}^{*}\right)\left(y-y^{*}\right) \\
& -\sigma \eta_{2}\left(1-q_{2} E_{2}\right)\left(x_{1}-x_{1}^{*}\right)\left(x_{2}-x_{2}^{*}\right), \\
\frac{d V_{3}}{d t}= & \eta_{1} \beta_{1}\left(x_{1}-x_{1}^{*}\right)\left(y-y^{*}\right)+\eta_{2} \beta_{2}\left(1-q_{2} E_{2}\right)\left(x_{2}-x_{2}^{*}\right)\left(y-y^{*}\right) .
\end{aligned}
$$


Then taking the time derivative of $V\left(x_{1}, x_{2}, y\right)$ along the trajectories of (2.1), after proper simplification [35], we have

$$
\begin{aligned}
\frac{d V\left(x_{1}, x_{2}, y\right)}{d t}= & \frac{d V_{1}}{d t}+\frac{d V_{2}}{d t}+\frac{d V_{3}}{d t} \\
= & -\frac{\eta_{1} r_{1}}{k_{1}}\left(x_{1}-x_{1}^{*}\right)^{2}-\eta_{1} \beta_{1}\left(x_{1}-x_{1}^{*}\right)\left(y-y^{*}\right) \\
& -\sigma \eta_{1}\left(1-q_{2} E_{2}\right)\left(x_{1}-x_{1}^{*}\right)\left(x_{2}-x_{2}^{*}\right) \\
& -\frac{\eta_{2} r_{2}}{k_{2}}\left(1-q_{2} E_{2}\right)^{2}\left(x_{2}-x_{2}^{*}\right)^{2}-\eta_{2} \beta_{2}\left(1-q_{2} E_{2}\right)\left(x_{2}-x_{2}^{*}\right)\left(y-y^{*}\right) \\
& -\sigma \eta_{2}\left(1-q_{2} E_{2}\right)\left(x_{1}-x_{1}^{*}\right)\left(x_{2}-x_{2}^{*}\right)+\eta_{1} \beta_{1}\left(x_{1}-x_{1}^{*}\right)\left(y-y^{*}\right) \\
& +\eta_{2} \beta_{2}\left(1-q_{2} E_{2}\right)\left(x_{2}-x_{2}^{*}\right)\left(y-y^{*}\right) \\
= & -\left[\frac{\eta_{1} r_{1}}{k_{1}}\left(x_{1}-x_{1}^{*}\right)^{2}+\frac{\eta_{2} r_{2}}{k_{2}}\left(1-q_{2} E_{2}\right)^{2}\left(x_{2}-x_{2}^{*}\right)^{2}\right. \\
& \left.+\sigma\left(\eta_{1}+\eta_{2}\right)\left(1-q_{2} E_{2}\right)\left(x_{1}-x_{1}^{*}\right)\left(x_{2}-x_{2}^{*}\right)\right] \\
= & -X^{\mathrm{T}} A X,
\end{aligned}
$$

where $X=\left[\left(x_{1}-x_{1}^{*}\right),\left(x_{2}-x_{2}^{*}\right)\right]^{\mathrm{T}}$ and

$$
A=\left[\begin{array}{cc}
\frac{\eta_{1} r_{1}}{k_{1}} & \frac{\sigma}{2}\left(\eta_{1}+\eta_{2}\right)\left(1-q_{2} E_{2}\right) \\
\frac{\sigma}{2}\left(\eta_{1}+\eta_{2}\right)\left(1-q_{2} E_{2}\right) & \frac{\eta_{2} r_{2}}{k_{2}}\left(1-q_{2} E_{2}\right)^{2}
\end{array}\right] .
$$

Therefore $d V / d t<0$ if $A$ is positive definite. The $A$ is positive definite if the hypothesis of Theorem 2 is satisfied.

From the above analysis, we can see that the interior equilibrium is globally asymptotically stable under certain conditions. If the system is stable prior to harvesting, the harvested system does not change its stability.

\section{The yield problem of system (2.1)}

When it comes to biological conservation, there are many tools to do this. For example, the maximum sustainable yield (MSY) policy [37], the optimal taxation policy [38], the marine protected areas [7], the impulsive harvesting [39], and so on. As we all know, the maximum sustainable yield policy is a classic and old strategy. Despite it has many shortcomings [40], the concept of MSY has been a central theme for fisheries and legally adopted by Johannesburg Implementation Plan, for world fisheries to catch a maximum that is sustainable and to supposedly preserve over-fished stocks [41]. Ghosh et al. [41] defined the total maximum sustainable yield (MSTY) as the maximum of the sum of the yields obtained from both prey and predator under independent harvesting efforts. The MSTY is obtained when the yield is maximized with respect to $E_{1}$ and $E_{2}$. In this section, we investigate the maximum yield of system (2.1) and explore whether the system has MSTY.

Firstly, we give a brief description of the MSY problem of the two subsystems. The yield of system (3.1) is $Y\left(E_{1}\right)=q_{1} E_{1} \tilde{x}_{1}=\frac{q_{1} E_{1} m}{\eta_{1} \beta_{1}}$, which is a linear function of $E_{1}$. The yield of 
system (3.3) is $Y\left(E_{2}\right)=q_{2} E_{2} \bar{x}_{2}=\frac{m}{\eta_{2} \beta_{2}\left(1 / q_{2} E_{2}-1\right)}$. Further, $Y^{\prime}\left(E_{2}\right)=\frac{m q_{2}}{\eta_{2} \beta_{2}\left(1-q_{2} E_{2}\right)^{2}}>0$. We can see that the yield $Y\left(E_{i}\right)(i=1,2)$ increases with the increase of harvesting effort $E_{i}(i=1,2)$. Hence, there is no MSY in either of two subsystems. In system (2.1), we have

$$
\begin{aligned}
Y\left(E_{1}, E_{2}\right) & =q_{1} E_{1} x_{1}^{*}+q_{2} E_{2} x_{2}^{*} \\
& =\frac{q_{1} E_{1}\left(\nu_{3}-\eta_{2} \beta_{2}^{2} q_{1} E_{1}\right)}{v_{4}}+\frac{q_{2} E_{2}\left(v_{5}+v_{6} E_{1}\right)}{1-q_{2} E_{2}} \\
& =-\frac{q_{1}^{2} \eta_{2} \beta_{2}^{2}}{v_{4}} E_{1}^{2}+\left(\frac{q_{1} v_{3}}{v_{4}}+\frac{v_{6} q_{2} E_{2}}{1-q_{2} E_{2}}\right) E_{1}+\frac{v_{5} q_{2} E_{2}}{1-q_{2} E_{2}}
\end{aligned}
$$

where $v_{3}=m v_{2}-\eta_{2} \beta_{2} r_{2} \beta_{1}+\eta_{2} \beta_{2}^{2} r_{1}, v_{4}=\eta_{2} \beta_{2} v_{1}+\eta_{1} \beta_{1} v_{2}, v_{5}=\frac{v_{4} m-\eta_{1} \beta_{1} v_{3}}{v_{4} \eta_{2} \beta_{2}}, v_{6}=\frac{\eta_{1} \beta_{1} \eta_{2} \beta_{2}^{2} q_{1}}{\eta_{2} \beta_{2} v_{4}}$.

The Hessian matrix corresponding to $Y$ is

$$
H=\left[\begin{array}{cc}
-\frac{2 \beta_{2}^{2} \eta_{2} q_{1}^{2}}{v_{4}} & \frac{q_{2} v_{6}}{\left(q_{2} E_{2}-1\right)^{2}} \\
\frac{q_{2} v_{6}}{\left(q_{2} E_{2}-1\right)^{2}} & -\frac{2 q_{2}^{2}\left(v_{5}+E_{1} v_{6}\right)}{\left(q_{2} E_{2}-1\right)^{3}}
\end{array}\right]
$$

Obviously $\Delta_{1}=-\frac{2 \beta_{2}^{2} \eta_{2} q_{1}^{2}}{v_{4}}<0$ if $v_{4}>0$; meanwhile,

$$
\Delta_{2}=-\frac{q_{2}^{2}\left[\nu_{2} v_{6}^{2}+4 \beta_{2}^{2} \eta_{2} q_{1}^{2}\left(1-q_{2} E_{2}\right)\left(v_{5}+E_{1} v_{6}\right)\right]}{v_{4}\left(1-q_{2} E_{2}\right)^{4}}=-\frac{\beta_{1}^{2} \beta_{2}^{2} \eta_{1}^{2} q_{1}^{2} q_{2}^{2}}{v_{4}^{2}\left(1-q_{2} E_{2}\right)^{4}}<0 .
$$

For the existence of maximum of $Y$ at $\left(E_{1}^{*}, E_{2}^{*}\right)$, the sufficient conditions are not satisfied. If we fix the parameter $E_{2}$, let $Y$ reach its maximum at $E_{1}^{M}=\frac{v_{3} q_{1}\left(1-q_{2} E_{2}\right)+q_{2} E_{2} v_{6} v_{4}}{2 \eta_{2} \beta_{2}^{2} q_{1}^{2}\left(1-q_{2} E_{2}\right)}$ for $v_{4}>0$. Then substituting $E_{1}^{M}$ into (6.1), we have

$$
Y(E)=\frac{v_{4} v_{6}^{2}}{4 \beta_{2}^{2} \eta_{2} q_{1}^{2}} E^{2}+\frac{2 v_{5} \beta_{2}^{2} \eta_{2} q_{1}+v_{3} v_{6}}{2 \beta_{2}^{2} \eta_{2} q_{1}} E+\frac{v_{3}^{2}}{4 v_{4} \beta_{2}^{2} \eta_{2}},
$$

where $E=\frac{q_{2} E_{2}}{1-q_{2} E_{2}}$.

We find that $Y(E)$ is a quadratic function of $E$ going upwards for $v_{4}>0 . Y(E)$ can not get maximum in the feasible region about $E_{2}$. Functions in (6.1) and (6.3) can not take the maximum at the same time. We will give a concrete example to explain the problem in detail in Sect. 7.3.

Since there is no MSTY in system (2.1), we establish a control problem for yield to find a suboptimal control strategy. The form of objective function $G$ is expressed as follows:

$$
G\left(E_{1}, E_{2}\right)=\int_{0}^{t_{f}}\left(q_{1} E_{1} x_{1}+q_{2} E_{2} x_{2}\right) d t
$$

which is subjected to the state equation (2.1) and the control variables $E_{i}(t)$ are subjected to

$$
U=\left\{\left(E_{1}(t), E_{2}(t)\right) \in L^{1}\left[0, t_{f}\right] \times L^{1}\left[0, t_{f}\right] \mid a_{1} \leq E_{1}(t) \leq b_{1}, a_{2} \leq E_{2}(t) \leq b_{2}\right\},
$$

where $a_{i}, b_{i}(i=1,2)$ are fixed normal quantities. The initial condition is $\left(x_{1}(0), x_{2}(0)\right.$, $y(0))=\left(x_{10}, x_{20}, y_{0}\right)$. To ensure the sustainable survival of the species, we set the state constraints as $0<x_{1}(t)<k_{1}, 0<x_{2}(t)<k_{2}$, and $y(t)>0$ for all $t \in\left[0, t_{f}\right], k_{i}$ is the carrying ca- 
pacity of prey $x_{i}(i=1,2)$. We hope to get the maximum yield in $\left[0, t_{f}\right]$, which is equivalent to minimizing $-G$. The optimal control problem $(\mathrm{P})$ is as follows:

$$
\begin{aligned}
& \min _{E_{1}(t), E_{2}(t) \in U}-G\left(E_{1}(t), E_{2}(t)\right), \\
& \frac{d x_{1}}{d t}=x_{1} f_{1}\left(x_{1}, x_{2}, y, E_{1}, E_{2}\right), \quad x_{1}(0)=x_{10}, \\
& \frac{d x_{2}}{d t}=\left(1-q_{2} E_{2}\right) x_{2} f_{2}\left(x_{1}, x_{2}, y, E_{2}\right), \quad x_{2}(0)=x_{20}, \\
& \frac{d y}{d t}=y g\left(x_{1}, x_{2}, E_{2}\right), \quad y(0)=y_{0}, \\
& 0<x_{1}(t)<k_{1}, \quad 0<x_{2}(t)<k_{2}, \quad y(t)>0, \quad \forall t \in\left[0, t_{f}\right] .
\end{aligned}
$$

We use the computational algorithms based on the concept of control parametrization to solve the optimal control problem. First, we partition the interval $\left[0, t_{f}\right]$ into several subintervals, and the control variables $E_{i}(i=1,2)$ are approximated by piecewise constant functions with the instants of switching preassigned by the corresponding partition. Then, an optimal control problem is approximated by a corresponding optimal parameter selection problem which can be viewed as a mathematical programming problem, and hence is solvable by the existing optimization software packages [42, 43]. The relevant numerical experiment is shown in Sect. 7.3.

\section{Numerical simulations}

In this section, to make analytical studies more complete, we perform numerical simulations by MATLAB. The numerical simulations of systems (2.1), (3.1), and (3.3) have been carried out from the following four aspects.

\subsection{The role of the carrying capacity of prey $x_{i}(i=1,2)$}

The term carrying capacity was put forward by Leopold in his work [44] and is one of the most common concepts in wildlife management [45]. Many types of research [46, 47] have verified that carrying capacity makes a great difference in the predator-prey system. Next, we use numerical simulations to investigate the impact of carrying capacity $k_{i}(i=1,2)$ on the system result. We select $k_{1}$ and $k_{2}$ from three levels and the order of magnitude between them is 10 . The other parameter values are as follows. The time graph and path of model $(2.1)$ as $k_{i}(i=1,2)$ is changing with different orders of magnitude are given in Figure 2.

$$
\begin{array}{lllll}
r_{1}=2.09, & \beta_{1}=0.01, & q_{1}=0.04, & \eta_{1}=0.3, & \sigma=0.001, \\
r_{2}=2.07, & \beta_{2}=0.02, & q_{2}=0.01, & \eta_{2}=0.3, & m=0.05 .
\end{array}
$$

By simple calculation and observation, we can obtain that if we just change the magnitude of $k_{i}(i=1,2)$, the time for the system to reach equilibrium also increases exponentially (see Figure 2), and the range of $E_{1}$ used to make three species coexistence $\left(S^{*}\right)$ is also reduced when keeping the other parameters unchanged and $E_{2}<1 / q_{2}$. When the carrying capacity $k_{i}(i=1,2)$ is very large, the growth of prey species tends to increase exponentially, which is not realistic. Therefore, we choose suitable medium size values of $k_{i}(i=1,2)$ in the following numerical simulation. 

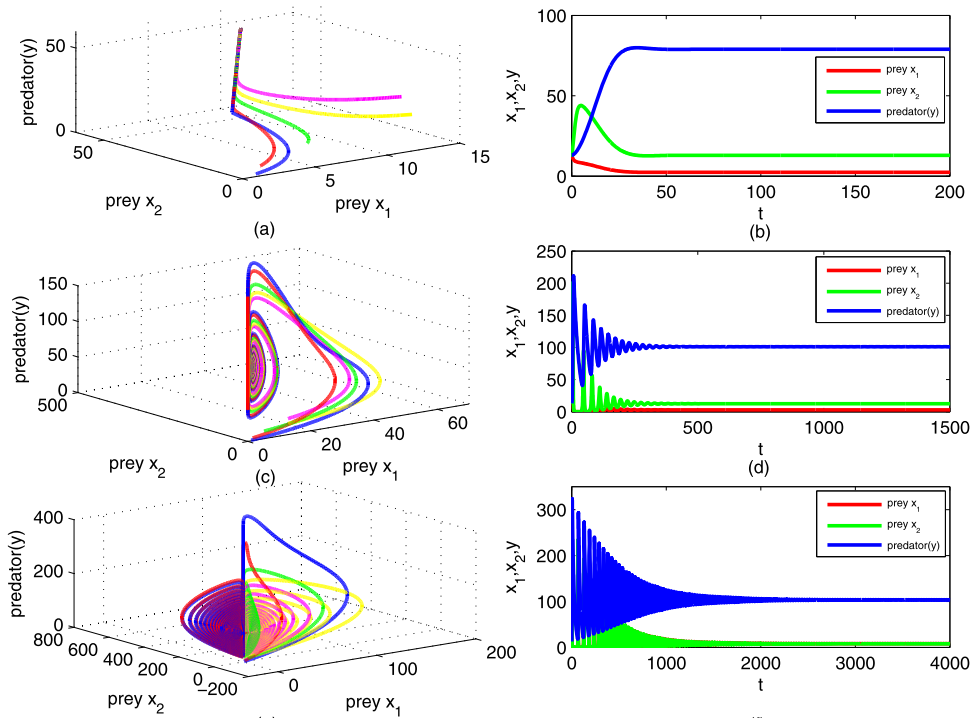

Figure 2 Phase portrait and time graph of model (2.1) around the interior equilibrium point. (a), (b) $k_{1}=20$, $k_{2}=30 .(\mathbf{c}),(\mathbf{d}) k_{1}=200, k_{2}=300 .(\mathbf{e}),(\mathbf{f}) k_{1}=2000, k_{2}=3000 .\left(E_{1}, E_{2}\right)=(26.2,45)$. The other parameter values are given in (7.1)

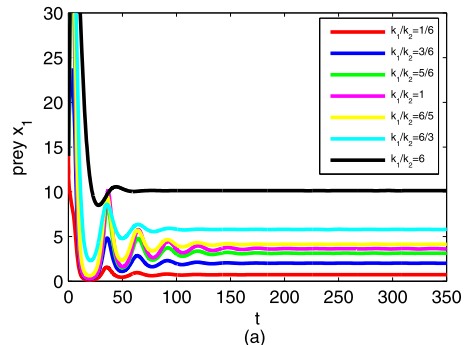

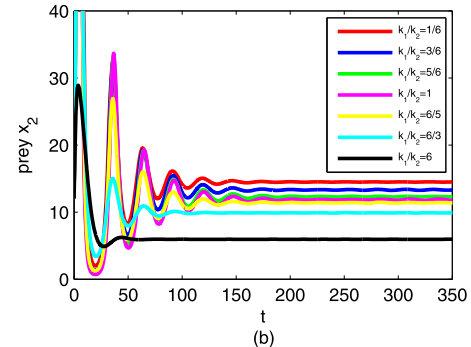

(b)

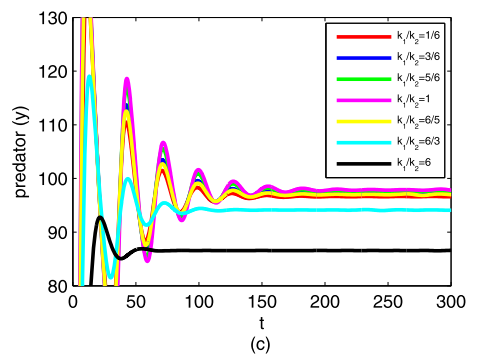

Figure 3 The changes of the biomass of system species with $k_{1} / k_{2}$. (a) Variations in prey $x_{1}$ with increasing time. (b) Variations in prey $x_{2}$ with increasing time. (c) Variations in predator $(y)$ with increasing time. The parameter values are given in $(7.1)$ and $\left(E_{1}, E_{2}\right)=(26.2,45)$

Further, we change the ratio between $k_{1}$ and $k_{2}$ to investigate the dynamics of three species using numerical simulation (see Figure 3). Simulation results show that the time for the system to reach equilibrium state decreases with the increase of ratio $k_{1} / k_{2}$ when $k_{1} / k_{2}>1$. On the contrary, the time for the system to reach equilibrium state increases with the increase of ratio $k_{1} / k_{2}$ when $k_{1} / k_{2}<1$. 


\subsection{The simulation about the model equations around three equilibrium points}

We simulate the model equations around various biologically significant steady states. In the previous analysis, we have identified two important boundary steady states $S_{3}\left(0, \bar{x}_{2}, \bar{y}\right)$ (without prey $x_{1}$ ) and $S_{4}\left(\tilde{x}_{1}, 0, \tilde{y}\right)$ (without prey $x_{2}$ ) together with the steady state of coexistence $S^{*}\left(x_{1}^{*}, x_{2}^{*}, y^{*}\right)$.

First, we calculate the two threshold harvesting efforts using the stability and existence conditions of three equilibrium points, then we select a stable state for each equilibrium point. The time evolution of the populations around $S_{3}$ is shown in Figure 4(a), which shows that the predator coexists stably with the second prey instead of the first one and the first prey goes to extinction. We have also shown the phase portrait around this equilibrium point in Figure 4(b). The time evolution of the populations around $S_{4}$, which is stable, is shown in Figure 5(a) and the relevant phase portrait is shown in Figure 5(b), which shows stable coexistence of the first prey and the predator.

Finally, we mainly consider the local dynamics of the unique interior equilibrium using numerical simulation. For better comparison, we take the following values:

$$
\begin{aligned}
& r_{1}=r_{2}=2, \quad k_{1}=k_{2}=200, \quad \beta_{1}=\beta_{2}=0.01, \\
& q_{1}=q_{2}=0.2, \quad \eta_{1}=\eta_{2}=0.4, \quad \sigma=0.008, \quad m=0.05 .
\end{aligned}
$$

The relevant functions are as follows:

$$
\left\{\begin{array}{l}
f_{1}\left(x_{1}, x_{2}, y, E_{1}, E_{2}\right)=2\left(1-\frac{x_{1}}{200}\right)-0.01 y-0.2 E_{1}-0.008\left(1-0.2 E_{2}\right) x_{2} \\
f_{2}\left(x_{1}, x_{2}, y, E_{2}\right)=2\left[1-\frac{\left(1-0.2 E_{2}\right) x_{2}}{200}\right]-0.01 y-0.008 x_{1} \\
g\left(x_{1}, x_{2}, E_{2}\right)=0.004 x_{1}+0.004\left(1-0.2 E_{2}\right) x_{2}-0.05
\end{array}\right.
$$
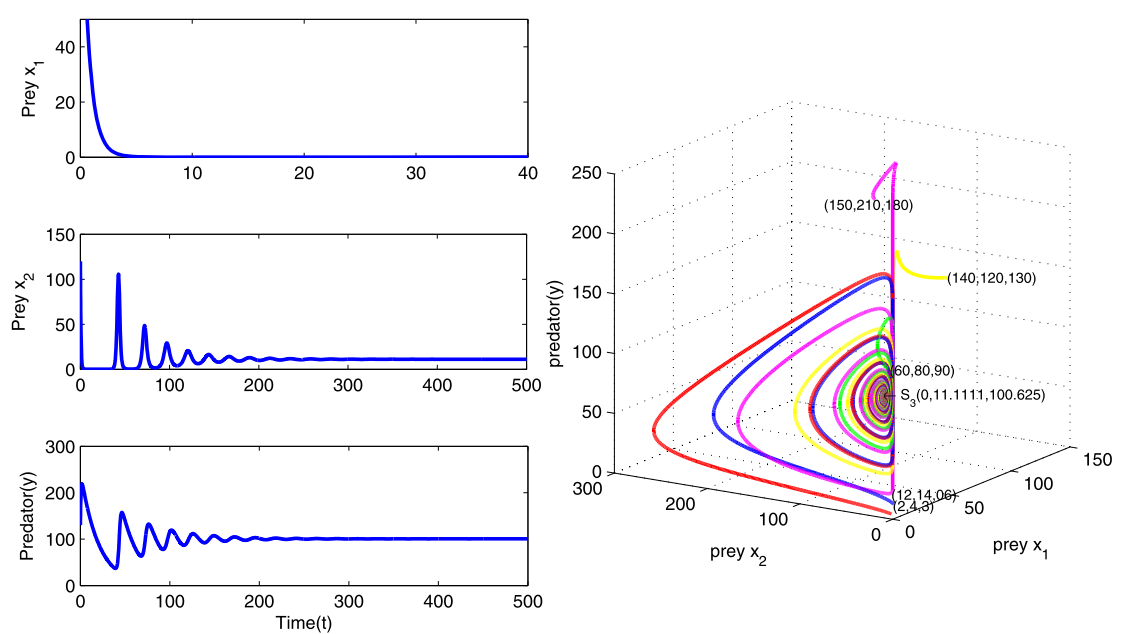

(a)

(b)

Figure 4 Numerical simulation of model $(2.1)$ around the boundary state $S_{3} . S_{3}(0,11.1111,100.625)$ with $E_{1}=30, E_{2}=25$. Different color curves represent different initial conditions. The other parameter values are given in $(7.1)$ and $\left(k_{1}, k_{2}\right)=(200,300)$ 

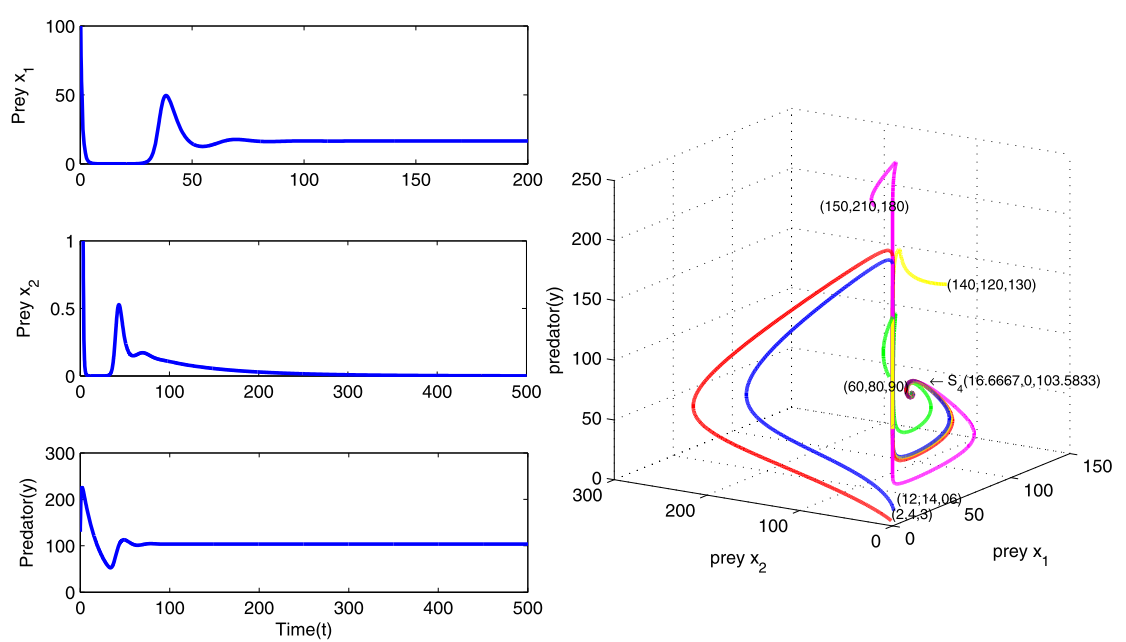

(a)

(b)

Figure 5 Numerical simulation of model (2.1) around the boundary state $S_{4} . S_{4}(16.6667,0,103.5833)$ with $E_{1}=22, E_{2}=35$. Different color curves represent different initial conditions. The other parameter values are given in $(7.1)$ and $\left(k_{1}, k_{2}\right)=(200,300)$

The interior equilibrium is

$$
S^{*}\left(x_{1}^{*}, x_{2}^{*}, y^{*}\right)=\left(6.25-50 E_{1}, \frac{50 E_{1}+6.25}{1-0.2 E_{2}}, 188.75-10 E_{1}\right) .
$$

The feasible condition for $S^{*}$ is $0<E_{1}<0.125$ and $0<E_{2}<5$. Moreover, the characteristic equation associated with the matrix $J\left(S^{*}\right)$ is given by $\lambda^{3}+\xi_{1} \lambda^{2}+\xi_{2} \lambda+\xi_{3}=0$, where

$$
\begin{aligned}
\xi_{1}= & 0.2890 \times 10^{-16} E_{1}-0.0125 E_{2}-0.1 E_{1} E_{2}+0.1250, \\
\xi_{2}= & 0.0220 E_{1}^{2} E_{2}-0.0097 E_{2}-0.0750 E_{1} E_{2}-0.0050 E_{1}-0.0900 E_{1}^{2}+0.0958, \\
\xi_{3}= & 0.0000125 E_{1} E_{2}-0.000236 E_{2}-0.0000625 E_{1}+0.0151 E_{1}^{2} E_{2} \\
& -0.0008 E_{1}^{3} E_{2}-0.0755 E_{1}^{2}+0.0040 E_{1}^{3}+0.0012 .
\end{aligned}
$$

Further, we have

$$
\begin{aligned}
\xi_{1} \xi_{2}-\xi_{3}= & \left(-0.0022 E_{1}^{3}+0.00722 E_{1}^{2}+0.0019 E_{1}+0.0001\right) E_{2}^{2} \\
& +\left(0.0098 E_{1}^{3}-0.0107 E_{1}^{2}-0.0189 E_{1}-0.0022\right) E_{2} \\
& -0.004 E_{1}^{3}+0.0643 E_{1}^{2}-0.0006 E_{1}+0.01079
\end{aligned}
$$

To investigate its stability, we examine the signs of functions $\xi_{1}, \xi_{2}$ and $\xi_{1} \xi_{2}-\xi_{3}$.

1. If $\xi_{1}>0$, we have $E_{2}<\frac{0.2890 \times 10^{-16} E_{1}+0.125}{0.0125+0.1 E_{1}}<10$, which is obviously true.

2. If $\xi_{3}>0$, we have $\phi\left(E_{2}-5\right)>0$, where $\phi=-0.8 E_{1}^{3}+15.1 E_{1}^{2}+0.0125 E_{1}-0.236$. Further, $\phi^{\prime}=-2.4 E_{1}^{2}+30.2 E_{1}+0.0125$, the two roots of this equation $\phi^{\prime}=0$ are -0.0004139 and 12.5837 . In $(0,12.5837), \phi^{\prime}>0$, therefore $\phi$ is monotonically increasing. Due to $\phi(0.125)=-0.0000625<0$, we have $\phi<0$ in the existent domain of $S^{*}$. Then we have $E_{2}<5$, which is consistent with the existence condition. 

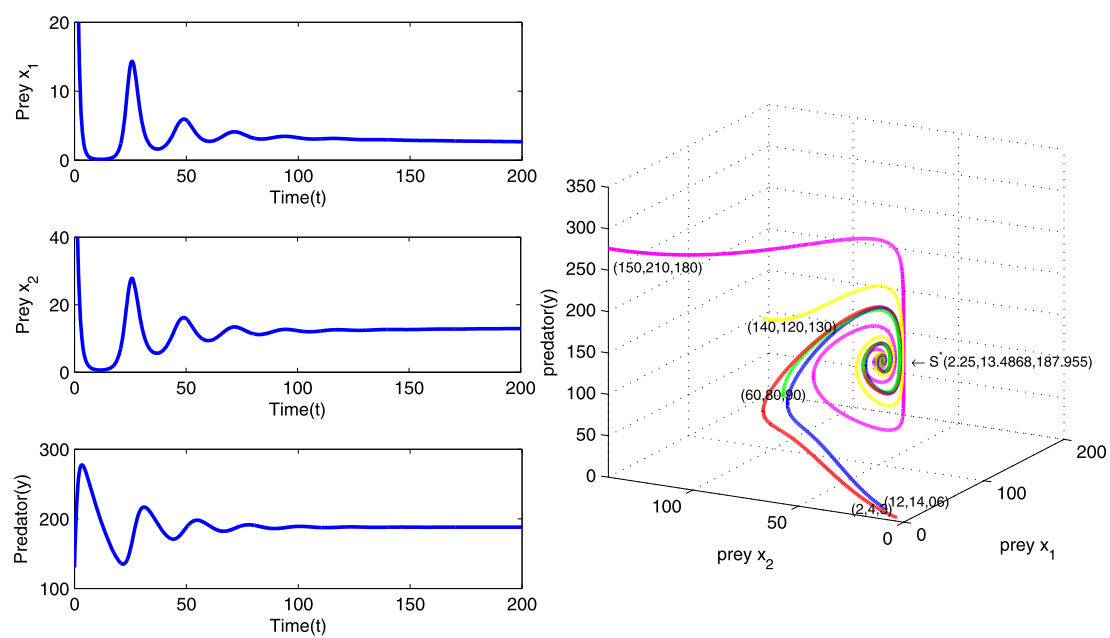

(a)

(b)

Figure 6 Numerical simulation of model (2.1) around the interior equilibrium point $S^{*}$.

$S^{*}(2.25,13.4868,187.955)$ with $E_{1}=0.08, E_{2}=1.2$. Different color curves represent different initial conditions. The other parameter values are given in (7.2)

3. Consider $\xi_{1} \xi_{2}-\xi_{3}$, let

$$
\begin{aligned}
& \phi_{1}=-0.0022 E_{1}^{3}+0.00722 E_{1}^{2}+0.0019 E_{1}+0.0001 \\
& \phi_{2}=0.0098 E_{1}^{3}-0.0107 E_{1}^{2}-0.0189 E_{1}-0.0022 \\
& \phi_{3}=-0.004 E_{1}^{3}+0.0643 E_{1}^{2}-0.0006 E_{1}+0.01079
\end{aligned}
$$

Then $\xi_{1} \xi_{2}-\xi_{3}=\phi_{1} E_{2}^{2}+\phi_{2} E_{2}+\phi_{3}$. After computation, we have $\phi_{1}>0$ and $\Delta=\phi_{2}^{2}-4 \phi_{1} \phi_{3}<0$ when $E_{1}$ belongs to $(0,0.125)$, therefore, $\xi_{1} \xi_{2}-\xi_{3}>0$.

From the above analysis, the unique interior equilibrium is locally asymptotically stable. Next we simulate the model equations around the interior equilibrium point $S^{*}$. The resulting time and phase plot are shown in Figure 6.

\subsection{Simulation for the yield problem of system (2.1)}

Let us give a concrete example to analyze the yield problem of system (2.1). The relevant parameters, except $m=0.4, \sigma=0.0035$, are given in $(7.1)$ and $\left(k_{1}, k_{2}\right)=(200,300)$. The interior equilibrium is

$$
\left(121.2296-4.6110 E_{1},-\frac{0.0138 E_{1}+0.0363}{0.00006 E_{2}-0.006}, 0.0115 E_{1}+80.1969\right) \text {. }
$$

The feasible condition is $0 \leq E_{1}<26.29139,0 \leq E_{2}<100$. Consider that the yield function has a maximum value of the parameter $E_{1}$ when $E_{2}$ is fixed. Then we have $E_{1}^{M}=$ $\frac{0.020833\left(331 E_{2}-63,100\right)}{E_{2}-100}$ and $Y(E)=7.204611 E^{2}-36.359270 E+31.873279$. The feasible region of $E$ is $0<E<2.103333$, when $E=2.103333$, namely $E_{2}=67.776584$, we have $E_{1}^{M}=26.29139$, then $x_{1}^{*}=0$. Further, $Y\left(E_{2}=0\right)=31.8732789$ and $Y\left(E_{2}=67.776584\right)=140.222222$. Since this is the case of independent harvesting strategy, it suggests that towards MSTY harvesting level, prey $x_{1}$ will be going extinct (see Figure 7 ). 

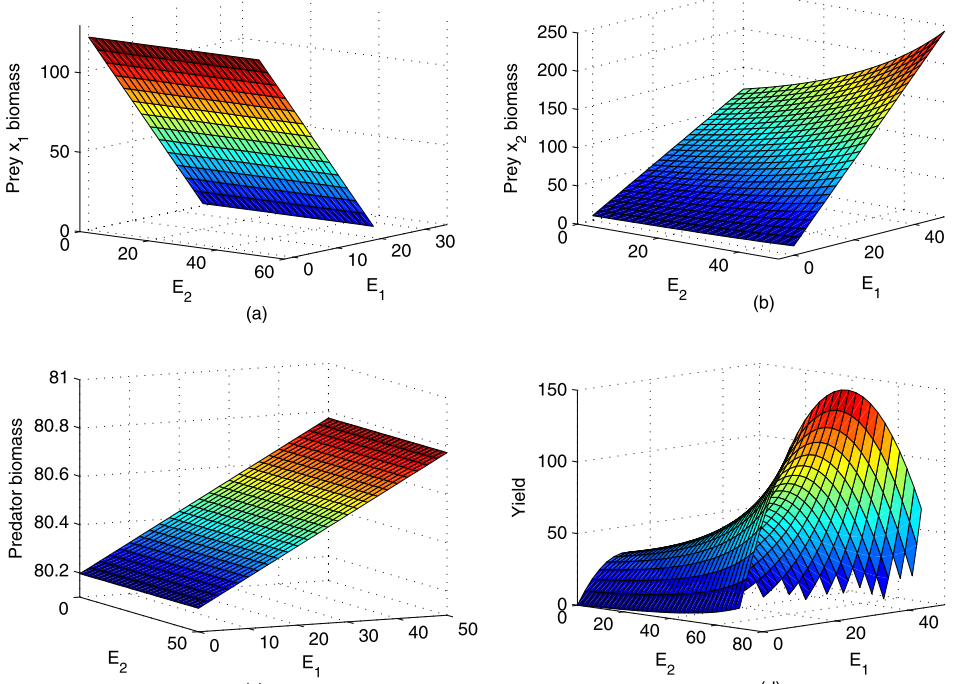

Figure 7 The changes of the biomass of system species and the yield. (a) Prey $x_{1}$ biomass varies with $E_{1}$ and $E_{2}$. (b) Prey $x_{2}$ biomass varies with $E_{1}$ and $E_{2}$. (c) The predator biomass varies with $E_{1}$ and $E_{2}$. (d) The yield from both prey and predator as function of $E_{1}$ and $E_{2}$. The relevant parameters except $d=0.4, \sigma=0.0035$ are given in $(7.1)$ and $\left(k_{1}, k_{2}\right)=(200,300)$

Table 1 The optimal control and states variables of $(P)$

\begin{tabular}{rrrrrr}
\hline \multicolumn{1}{l}{ Time } & Control 1 & Control 2 & \multicolumn{1}{c}{ State 1 } & \multicolumn{1}{c}{ State 2 } & \multicolumn{1}{c}{ State 3 } \\
\hline 0.0000 & 0.83430 & 0.00000 & 15.00000 & 15.00000 & 12.00000 \\
1.8182 & 5.16684 & 1.37425 & 109.00304 & 128.58783 & 16.10776 \\
3.6364 & 3.96670 & 0.88688 & 93.32653 & 125.22972 & 66.42204 \\
5.4545 & 1.09206 & 1.92634 & 71.50602 & 37.75527 & 113.98322 \\
7.2727 & 3.41622 & 0.00000 & 80.79575 & 13.47770 & 105.64105 \\
9.0909 & 6.96972 & 0.00000 & 89.77432 & 8.50216 & 90.45973 \\
10.9091 & 21.48043 & 0.00000 & 91.47356 & 8.84428 & 77.90937 \\
12.7273 & 23.47555 & 1.99791 & 59.29581 & 16.42672 & 62.38116 \\
14.5455 & 12.68776 & 54.89466 & 50.81738 & 43.53919 & 54.60362 \\
16.3636 & 5.90543 & 90.59718 & 81.84325 & 72.67257 & 50.86236 \\
18.1818 & 26.29119 & 87.90424 & 122.91470 & 81.59493 & 47.76096 \\
20.0000 & 26.29119 & 87.90424 & 67.05375 & 97.18600 & 41.09602 \\
\hline
\end{tabular}

Here we use the MISER 3 Optimal Control Toolbox of MATLAB to solve problem (6.5). The relevant parameters except $m=0.4, \sigma=0.0035$ are given in (7.1) and $\left(k_{1}, k_{2}\right)=$ $(200,300)$. According to the existence condition of interior equilibrium point, the range of control parameters $E_{i}(i=1,2)$ is given as $0 \leq E_{1} \leq 26.29139,0 \leq E_{1} \leq 99.9999$. In fact, the value range of parameter $E_{2}$ is $[0,100)$. To guarantee that model (2.1) is significant, the condition $1-q_{2} E_{2} \neq 0$ should be satisfied. So we set $b_{2}$ to 99.9999 . The initial condition is $\left(x_{1}(0), x_{2}(0), y(0)\right)=(15,15,12)$ and $t_{f}=20$. One possible optimal solution is shown in Table 1 and Figure 8. We can see that the continuous inequality constraints are stratified and the corresponding optimal function value is 943.4639 . 

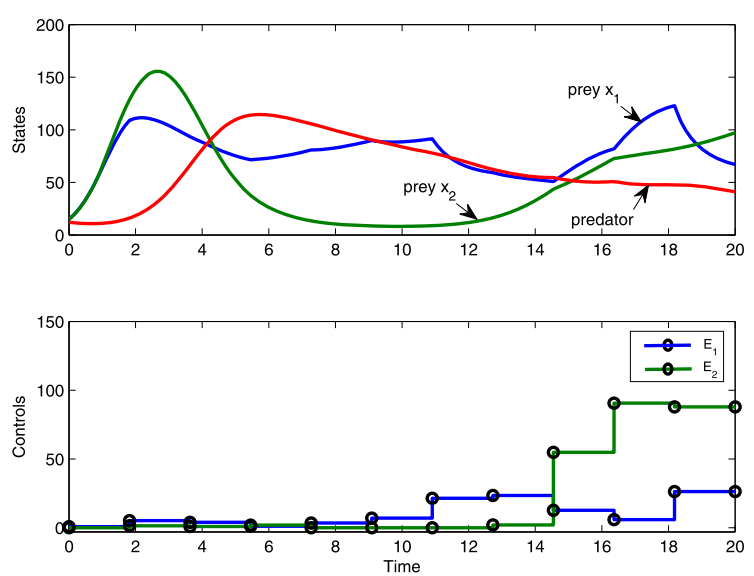

Figure 8 The optimal states and control of problem (P)

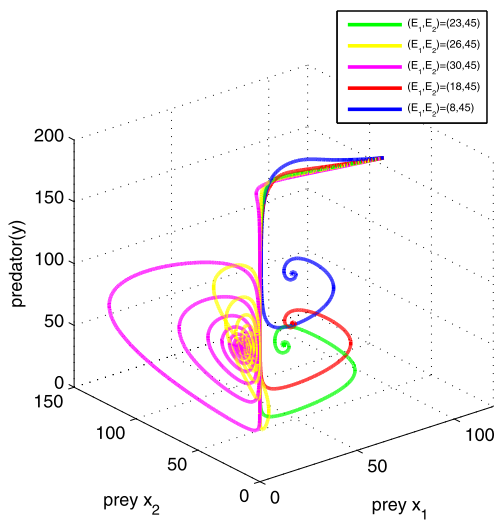

(a)
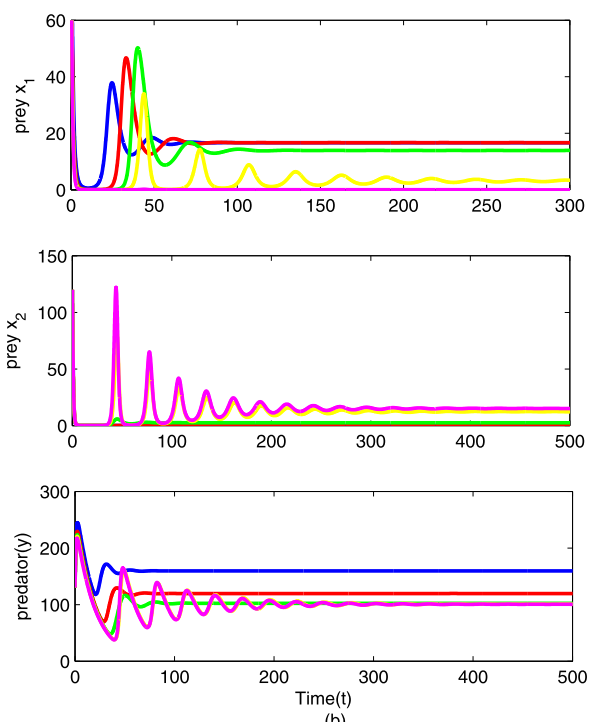

(b)

Figure 9 Different solution plots as $E_{1}$ increases. Keeping the other parameters unchanged (see Table 2)

\subsection{Influence of two forms of harvesting functions for systems (2.1), (3.1), and}

To compare the two forms of harvesting functions better, we perform the numerical simulations of model (2.1) with $E_{1}$ and $E_{2}$ changing respectively (see Figures 9, 10,11). The parameter values used in Figures 9, 10, 11 are given in Table 2.

For subsystems (3.1) and (3.3), we keep the corresponding parameters except $E_{1}$ and $E_{2}$ the same, then draw the time graphs and different solution plots of models (3.1) and (3.3), respectively, as $E_{i}(i=1,2)$ increase (see Table 3) (see Figure 12). In addition, we study the effect of the harvesting function term on the two subsystems by periodically changing the harvesting effort respectively. Take $T=1000$ as the period of change, make other parameter values fixed, let the initial species level of the next period be the species level at the end of the previous period, and do not change the harvesting effort in every 

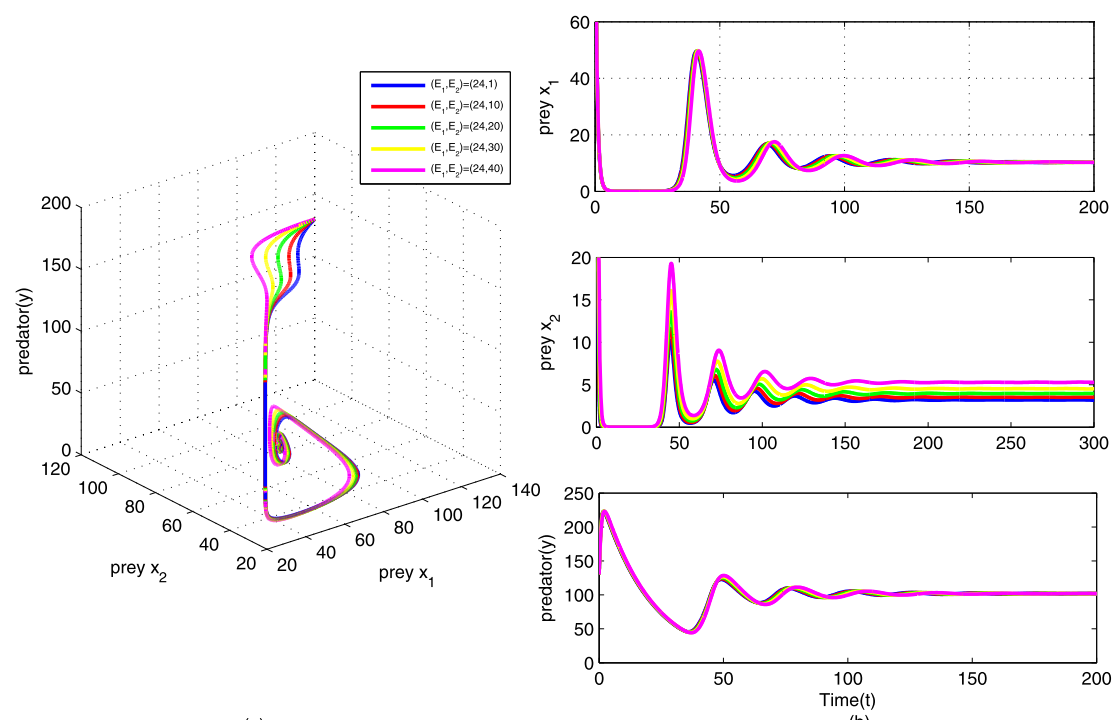

Figure 10 Different solution plots as $E_{2}$ increases. Keeping the other parameters unchanged (see Table 2)

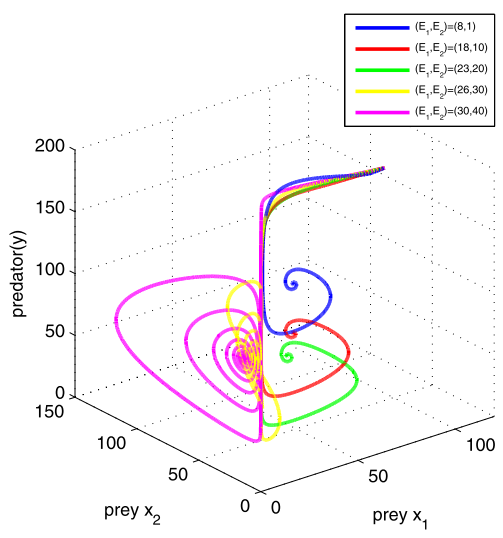

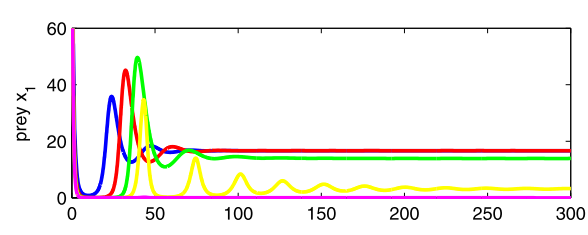
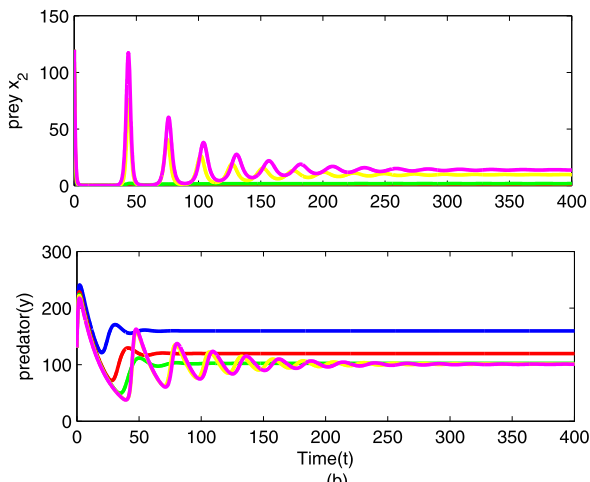

Figure 11 Different solution plots as both $E_{1}$ and $E_{2}$ increase. See Table 2

week period, then observe the population dynamic (see Figure 13). We take the relevant parameters except $E_{1}$ and $E_{2}$ as follows:

$$
\begin{array}{lll}
r_{1}=r_{2}=0.3, & k_{1}=k_{2}=100, & \beta_{1}=\beta_{2}=0.02, \\
q_{1}=q_{2}=0.2, & \eta_{1}=\eta_{2}=0.5, & m=0.05 .
\end{array}
$$

From Figures 9, 10, 11, by controlling the two harvesting efforts $E_{1}$ and $E_{2}$, we can discover that if we just change the parameter $E_{1}$, the number of three species in the final state of system (2.1) varies greatly; on the contrary, the numerical difference of the final state of 
Table 2 The parameter values of $E_{1}$ and $E_{2}$ used in Figures 9, 10, 11

\begin{tabular}{|c|c|c|c|c|}
\hline No. & Fixed parameters & $\left(E_{1}, E_{2}\right)$ & $S^{*}\left(x_{1}^{*}, x_{2}^{*}, y^{*}\right)$ & Figure \\
\hline 1 & $\begin{array}{l}k_{1}=200, k_{2}=300 \\
r_{i}, \beta_{i}, q_{i}, \eta_{i}, \sigma \text { and } m \\
\text { are the same as (7.1) }\end{array}$ & $(8,45)$ & Not exist & Figure 9(blue) \\
\hline 2 & ........... & $(18,45)$ & Not exist & Figure 9 (red) \\
\hline 3 & & $(23,45)$ & $(13.9075,2.5083,102.3287)$ & Figure 9(green) \\
\hline 4 & & $(26,45)$ & $(3.1693,12.2704,101.0132)$ & Figure 9(yellow) \\
\hline 5 & & $(30,45)$ & Not exist & Figure 9 (magenta) \\
\hline 6 & & $(24,1)$ & $(10.3281,3.2013,101.8902)$ & Figure 10(blue) \\
\hline 7 & $\ldots$ & $(24,10)$ & $(10.3281,3.5214,101.8902)$ & Figure 10(red) \\
\hline 8 & & $(24,20)$ & $(10.3281,3.9616,101.8902)$ & Figure 10(green) \\
\hline 9 & $\ldots \ldots \ldots \ldots$ & $(24,30)$ & $(10.3281,4.5275,101.8902)$ & Figure 10(yellow) \\
\hline 10 & $\ldots \ldots \ldots \ldots$ & $(24,40)$ & $(10.3281,5.2821,101.8902)$ & Figure 10 (magenta) \\
\hline 11 & & $(8,1)$ & Not exist & Figure 11 (blue) \\
\hline 12 & $\ldots \ldots \ldots \ldots$ & $(18,10)$ & Not exist & Figure 11 (red) \\
\hline 13 & $\ldots \ldots \ldots \ldots$ & $(23,20)$ & $(13.9075,1.7245,102.3287)$ & Figure 11 (green) \\
\hline 14 & & $(26,30)$ & $(3.1693,9.6410,101.0132)$ & Figure 11 (yellow) \\
\hline 15 & $\ldots$ & $(30,40)$ & Not exist & Figure 11 (magenta) \\
\hline
\end{tabular}

Table 3 The parameter values of $E_{1}$ and $E_{2}$ used in Figure 12

\begin{tabular}{lllll}
\hline$E_{i}(i=1,2)$ & $S_{1}^{*}$ of $(3.1)$ & Figure & $S_{2}^{*}$ of $(3.3)$ & Figure \\
\hline 0.4 & $(5,10.25)$ & Figure 12(a)(b)(blue) & $(5.4348,14.25)$ & Figure 12(c)(d)(blue) \\
0.8 & $(5,6.25)$ & Figure 12(a)(b)(red) & $(5.9524,14.25)$ & Figure 12(c)(d)(red) \\
1.2 & $(5,2.25)$ & Figure 12(a)(b)(yellow) & $(6.5789,14.25)$ & Figure 12(c)(d)(yellow) \\
1.6 & Not exist & Figure 12(a)(b)(green) & $(7.3529,14.25)$ & Figure 12(c)(d)(green) \\
2 & Not exist & Figure 12(a)(b)(magenta) & $(8.3333,14.25)$ & Figure 12(c)(d)(magenta) \\
\hline
\end{tabular}

system (2.1) is tiny except for prey $x_{2}$ species if we only change $E_{2}$. Further, from Figure 12, comparing with the coexistence state $S_{1}^{*}$ and $S_{2}^{*}$, as the intensity of capturing increases, the amount of prey $x_{1}$ remains unchanged finally, and the amount of the relevant predator decreases in system (3.1), while for system (3.3), the opposite is the case. The amount of prey $x_{2}$ increases and the amount of the relevant predator stays the same when the system turns to be stable finally.

From Figure 13, we can find that, for system (3.1), when the amount of harvesting effort is changed regularly based on the previous level of the population, the ecosystem will produce large fluctuations and even the risk of extinction exists. However, as for system (3.3), when the system tends to balance the appropriate change in the amount of harvesting effort, the system will produce a small range of fluctuations, and finally tend to balance, which is consistent with the global asymptotic stability of the internal equilibrium point and more in line with the development law of the real ecosystem. When the system achieves a stable equilibrium state of coexistence, increasing or decreasing harvesting will not easily break the balance of the system in that the ecosystem has the ability to repair itself.

Through the above analysis, we draw an interesting conclusion: the growth level of the predator-prey system under the effect of the new form of harvesting function is better than that under the impact of the traditional form, which may be a better reflection of the role of human-made disturbance in the development of a biological system. Under the same condition, the effect of $E_{2}$ on predation system (2.1) is more significant than that of $E_{1}$. Combined with the analysis of maximum yield (Sect. 6), harvesting may allow the population to grow faster. We can call it the incentive mechanism of human disturbance. 

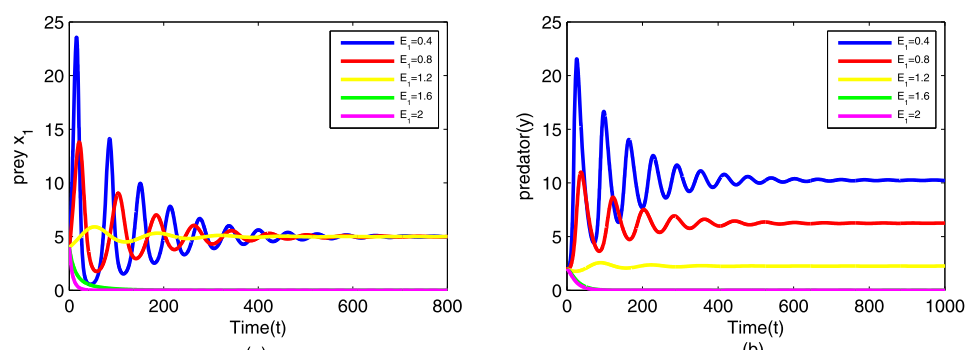

(a)
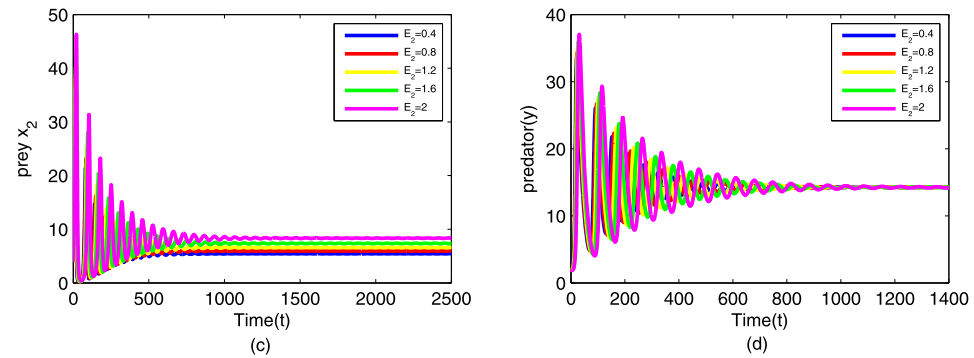

Figure 12 Path of the system species as $E_{1}\left(E_{2}\right)$ increases. (a), (b) Path of prey species $x_{1}$ and predator species $y$ of system (3.1) as $E_{1}$ increases (see Table 3 ) keeping the other parameters unchanged. (c), (d) Path of prey species $x_{2}$ and predator species $y$ of system (3.3) as $E_{2}$ increases (see Table 3) keeping the other parameters unchanged
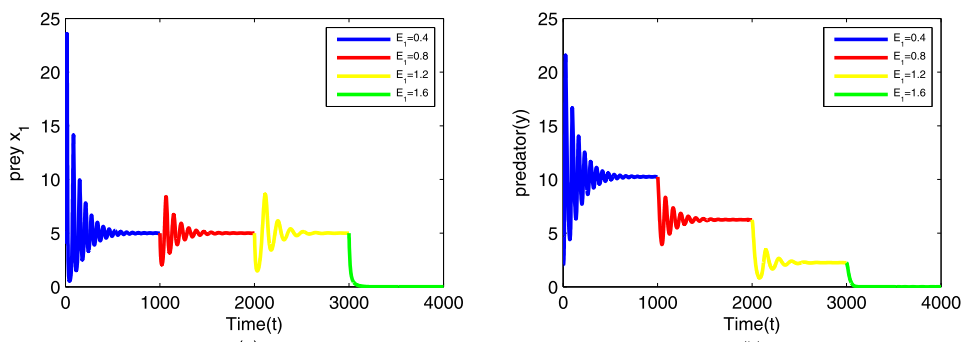

(a)
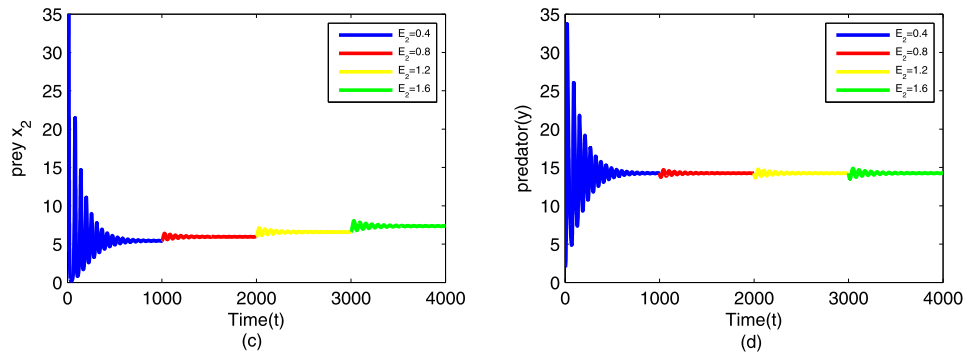

Figure 13 Path of the system species as $E_{1}\left(E_{2}\right)$ increases periodically. (a), (b) Path of prey species $x_{1}$ and predator species $y$ as $E_{1}$ increases periodically. The other parameter values are given in (7.5). (c), (d) Path of prey species $x_{2}$ and predator species $y$ as $E_{2}$ increases periodically. The other parameter values are given in (7.5)

It is likely that if we regard human intervention as an incentive factor that may promote the growth level of the population, then the population at equilibrium will increase in the long run. 


\section{Discussion and concluding remarks}

This paper has been conducting thorough research on the two-prey one-predator system, in which the harvesting function for prey $x_{1}$ adopts the traditional form and the other harvesting function for prey $x_{2}$ takes the new form. For drawing a precise comparison, we make two prey species have the same kind of growth function and functional response of the predator.

We focus on the stability of system (2.1). It has been proved that the positive interior equilibrium solution $S^{*}\left(x_{1}^{*}, x_{2}^{*}, y^{*}\right)$ is globally asymptotically stable under certain conditions (Theorem 2). Further, from the comparison between two subsystems (3.1) and (3.3), we find that the new form of harvesting function refines the effects of human intervention, which shows that harvesting prey affects not only the growth of prey population but also the growth of predator population.

To obtain the complete analytical studies, we apply numerical simulations to verify the results from four aspects: investigating the role of the carrying capacity of prey (see Sect. 7.1), simulating the model equations around four equilibrium points (see Sect. 7.2), investigating the problem of maximum sustainable yield and dynamic optimal yield in finite time (see Sect. 6 and 7.3), and studying the influence of two forms of harvesting functions for systems (2.1), (3.1), and (3.3) (see Sect. 7.4). Through the method of controlling variables, on the one hand, the dynamic behavior of system (2.1) is analyzed; on the other hand, the effects of two forms of harvesting function on systems (2.1), (3.1), and (3.3) are studied. Taking the specific parameters of the two prey species to the same value, we investigate the existence and stability of interior equilibrium under the influence of two kinds of harvesting functions. Comparing systems (3.1) and (3.3), though the new model system shows similar dynamical behaviors as the traditional model in which the harvesting function appears as a separate item, the emphases of the two kinds of systems are different (see Figure 1, in which process (a) emphasizes the effect of harvesting, while process (b) emphasizes the change of the system itself after harvesting). By analyzing the stability of the equilibrium points and the growth level of the predator-prey system, we find that the effect of $E_{2}$ on predator system (2.1) is more significant than that of $E_{1}$. Under the influence of $E_{1}$, the overall level of population number at which the system is stable decreases as effort increases, but for $E_{2}$, the opposite is the case.

If we regard human intervention as an incentive factor which may promote the growth level of the population, then the population at equilibrium will increase as shown in Table 3 and Figure 12. Combined with the analysis of the yield problem, harvesting may allow the population to grow faster. Let us consider the fish as a single population which follows a simple logistic, and the population subject to the proportional harvesting. The maximum sustainable yield is approached when the optimum harvesting effort of $e_{\mathrm{opt}}=r / 2$ is applied, and the population arrives at $k / 2$, which is the fastest growing point of population growth [30]. If we harvest the species at the inflexion point, the population level will remain optimal. By capturing and training species continuously, we may keep it as maximum biomass, then the harvesting may promote population growth and reproduction.

In this paper, instead of denying the traditional form, we propose a new way to study this kind of harvested predator-prey model. As shown by (3.5), the terms $\delta_{1}\left(x_{2}, y, E_{2}\right)$ and $\delta_{2}\left(x_{2}, y, E_{2}\right)$ seem to be a new harvesting function for the traditional form, which illus- 
trates the predator-prey system more appropriately. If we change the growth pattern, the response function, or the harvesting function of model system (2.1), then more thorough conclusions would be obtained.

\section{Appendix 1}

The Jacobian evaluated at the boundary equilibrium $S_{3}$ is given by

$$
J\left(S_{3}\right)=\left[\begin{array}{ccc}
r_{1}-q_{1} E_{1}+\frac{\beta_{1} r_{2}\left(m-\beta_{2} \eta_{2} k_{2}\right)}{\beta_{2}^{2} \eta_{2} k_{2}}-\frac{m \sigma}{\beta_{2} \eta_{2}} & 0 & 0 \\
-\frac{m \sigma}{\beta_{2} \eta_{2}} & \frac{m r_{2}\left(q_{2} E_{2}-1\right)}{\beta_{2} \eta_{2} k_{2}} & -\frac{m}{\eta_{2}} \\
-\frac{\beta_{1} \eta_{1} r_{2}\left(m-\beta_{2} \eta_{2} k_{2}\right)}{\beta_{2}^{2} \eta_{2} k_{2}} & \frac{r_{2}\left(m-\beta_{2} \eta_{2} k_{2}\right)\left(q_{2} E_{2}-1\right)}{\beta_{2} k_{2}} & 0
\end{array}\right]
$$

One of the eigenvalues of $J\left(S_{3}\right)$ is given by $\bar{\lambda}_{1}$ and the other two eigenvalues $\bar{\lambda}_{ \pm}$are given by the eigenvalues of the following $2 \times 2$ matrix:

$$
\bar{J}\left(S_{3}\right)=\left[\begin{array}{cc}
\frac{m r_{2}\left(q_{2} E_{2}-1\right)}{\beta_{2} \eta_{2} k_{2}} & -\frac{m}{\eta_{2}} \\
\frac{r_{2}\left(m-\beta_{2} \eta_{2} k_{2}\right)\left(q_{2} E_{2}-1\right)}{\beta_{2} k_{2}} & 0
\end{array}\right] .
$$

The characteristic equation associated with the matrix $\bar{J}\left(S_{3}\right)$ is given by

$$
\lambda^{2}-\frac{m r_{2}\left(q_{2} E_{2}-1\right)}{\beta_{2} \eta_{2} k_{2}} \lambda+\frac{m r_{2}\left(m-\beta_{2} \eta_{2} k_{2}\right)\left(q_{2} E_{2}-1\right)}{\eta_{2} \beta_{2} k_{2}}=0 .
$$

\section{Appendix 2}

The Jacobian evaluated at the boundary equilibrium $S_{4}$ is given by

$$
J\left(S_{4}\right)=\left[\begin{array}{ccc}
-\frac{m r_{1}}{\beta_{1} \eta_{1} k_{1}} & B_{1} & -\frac{m}{\eta_{1}} \\
0 & B_{1}-\frac{\beta_{2}\left(q_{2} E_{2}-1\right) B_{2}}{\beta_{1}}-r_{2}\left(q_{2} E_{2}-1\right) & 0 \\
-\beta_{1} \eta_{1} & \frac{\beta_{2} \eta_{2}\left(q_{2} E_{2}-1\right) B_{2}}{\beta_{1}} & 0
\end{array}\right],
$$

where

$$
B_{1}=\frac{m \sigma\left(q_{2} E_{2}-1\right)}{\beta_{1} \eta_{1}}, \quad B_{2}=q_{1} E_{1}+r_{1}\left(\frac{m}{\beta_{1} \eta_{1} k_{1}}-1\right) .
$$

The characteristic equation associated with the matrix $J\left(S_{4}\right)$ is given by $\lambda^{3}+\varphi_{1} \lambda^{2}+\varphi_{2} \lambda+$ $\varphi_{3}=0$, where

$$
\begin{aligned}
\varphi_{1} & =\frac{m r_{1}}{\beta_{1} \eta_{1} k_{1}}-B_{1}+\frac{\beta_{2}\left(q_{2} E_{2}-1\right) B_{2}}{\beta_{1}}+r_{2}\left(q_{2} E_{2}-1\right) \\
\varphi_{2} & =-\frac{m r_{1}}{\beta_{1} \eta_{1} k_{1}}\left[B_{1}-\frac{\beta_{2}\left(q_{2} E_{2}-1\right) B_{2}}{\beta_{1}}-r_{2}\left(q_{2} E_{2}-1\right)\right]-m B_{2} \\
\varphi_{3} & =m B_{2}\left[B_{1}-\left(\frac{\beta_{2} B_{2}}{\beta_{1}}+r_{2}\right)\left(q_{2} E_{2}-1\right)\right] .
\end{aligned}
$$




\section{Appendix 3}

The Jacobian evaluated at the interior equilibrium point $S^{*}$ is given by

$$
J\left(S^{*}\right)=\left[\begin{array}{ccc}
\rho_{11} & \rho_{12} & \rho_{13} \\
\rho_{21} & \rho_{22} & \rho_{23} \\
\rho_{31} & \rho_{32} & 0
\end{array}\right],
$$

where

$$
\begin{aligned}
& \rho_{11}=\frac{\sigma\left(m C_{2}-\beta_{1} \eta_{1} C_{1}\right)}{C_{2} \beta_{2} \eta_{2}\left(q_{2} E_{2}-1\right)}-\beta_{1} y^{*}-r_{1}\left(\frac{C_{1}}{k_{1} C_{2}}-1\right)-\frac{r_{1} C_{1}}{k_{1} C_{2}}-q_{1} E_{1}, \quad \rho_{12}=-\frac{\sigma C_{1}}{C_{2}}, \\
& \rho_{13}=-\frac{\beta_{1} C_{1}}{C_{2}}, \quad \rho_{21}=\frac{\sigma C_{3}}{\left(q_{2} E_{2}-1\right) C_{2}}, \quad \rho_{23}=-\frac{\beta_{2} C_{3}}{C_{2}}, \\
& \rho_{22}=\left(q_{2} E_{2}-1\right)\left[\frac{2 r_{2}\left(1-q_{2} E_{2}\right) x_{2}^{*}}{k_{2}}+\beta_{2} y^{*}+\sigma x_{1}^{*}-r_{2}\right], \\
& \rho_{31}=\beta_{1} \eta_{1} y^{*}, \quad \rho_{32}=-\beta_{2} \eta_{2} y^{*}\left(q_{2} E_{2}-1\right), \\
& C_{1}=m v_{2}-\beta_{2} \eta_{2}\left[\beta_{1} r_{2}-\beta_{2}\left(r_{1}-q_{1} E_{1}\right)\right], \quad C_{2}=\beta_{1} \eta_{1} v_{2}+\beta_{2} \eta_{2} v_{1}, \\
& C_{3}=m v_{1}+\beta_{1}^{2} \eta_{1} r_{2}-\beta_{1} \beta_{2} \eta_{1}\left(r_{1}-q_{1} E_{1}\right) .
\end{aligned}
$$

The characteristic equation associated with the matrix $J\left(S^{*}\right)$ is given by $\lambda^{3}+\xi_{1} \lambda^{2}+\xi_{2} \lambda+$ $\xi_{3}=0$, where

$$
\begin{aligned}
& \xi_{1}=-\left(\rho_{11}+\rho_{22}\right), \quad \xi_{2}=-\rho_{23} \rho_{32}-\rho_{12} \rho_{21}-\rho_{31} \rho_{13}+\rho_{11} \rho_{22}, \\
& \xi_{3}=\rho_{11} \rho_{32} \rho_{23}-\rho_{12} \rho_{23} \rho_{31}-\rho_{13} \rho_{21} \rho_{32}+\rho_{13} \rho_{31} \rho_{22} .
\end{aligned}
$$

\section{Acknowledgements}

The authors would like to express gratitude to all those who helped us during the writing of this paper.

Funding

This research was supported by the Natural Science Foundation of Jilin Province of China (20180101221 JC).

Availability of data and materials

Not applicable.

\section{Competing interests}

The authors declare that they have no competing interests.

\section{Authors' contributions}

The authors conceived of the study, drafted the manuscript, read and approved the final manuscript.

\section{Publisher's Note}

Springer Nature remains neutral with regard to jurisdictional claims in published maps and institutional affiliations.

Received: 5 September 2019 Accepted: 27 November 2019 Published online: 04 December 2019

\section{References}

1. LV, Y.F., Yuan, R., Pei, Y.Z:: A prey-predator model with harvesting for fishery resource with reserve area. Appl. Math. Model. 37, 3048-3062 (2013). https://doi.org/10.1016/j.apm.2012.07.030

2. Martin, A., Ruan, S.G.: Predator-prey models with delay and prey harvesting. J. Math. Biol. 43, 247-267 (2001). https://doi.org/10.1007/s002850100095

3. Guo, Y.J.: The stability of solutions for a fractional predator-prey system. Abstr. Appl. Anal. 2014, Article ID 124145 (2014). https://doi.org/10.1155/2014/124145 
4. Jiang, D., Ji, C.Y., Li, X.Y., O'Regan, D.: Analysis of autonomous Lotka-Volterra competition systems with random perturbation. J. Math. Anal. Appl. 390, 582-595 (2012). https://doi.org/10.1016/j.jmaa.2011.12.049

5. Negi, K., Gakkhar, S.: Dynamics in a Beddington-DeAngelis prey-predator system with impulsive harvesting. Ecol. Model. 206, 421-430 (2007). https://doi.org/10.1016/j.ecolmodel.2007.04.007

6. Kar, T.K., Ghosh, B.: Sustainability and economic consequences of creating marine protected areas in multispecies multiactivity context. J. Theor. Biol. 318, 81-90 (2013). https://doi.org/10.1016/j.jtbi.2012.11.004

7. Reithe, S., Armstrong, C.W., Flaaten, O.: Marine protected areas in a welfare-based perspective. Mar. Policy 49, 29-36 (2014). https://doi.org/10.1016/j.marpol.2014.04.002

8. Ghosh, M.: Modeling prey-predator type fishery with reserve area. Int. J. Biomath. 3, 351-365 (2010). https://doi.org/10.1142/S1793524510000982

9. Wang, S., Huang, Q.D.: Bifurcation of nontrivial periodic solutions for a Beddington-DeAngelis interference model with impulsive biological control. Appl. Math. Model. 39, 1470-1479 (2015). https://doi.org/10.1016/j.apm.2014.09.011

10. Wang, S., Huang, Q.D.: The sterile insect release technique in a predator-prey system with monotone functional response. Electron. J. Qual. Theory Differ. Equ. (2016). https://doi.org/10.14232/ejgtde.2016.1.91

11. Srinivasu, P.D.N., Prasad, B.S.R.V.: Time optimal control of an additional food provided predator-prey system with applications to pest management and biological conservation. J. Math. Biol. 60, 591-613 (2010). https://doi.org/10.1007/s00285-009-0279-2

12. Terry, A.J.: Biocontrol in an impulsive predator-prey model. Math. Biosci. 256, 102-115 (2014). https://doi.org/10.1016/j.mbs.2014.08.009

13. Jana, S., Guria, S., Das, U., Kar, T.K., Ghorai, A.: Effect of harvesting and infection on predator in a prey-predator system. Nonlinear Dyn. 81, 917-930 (2015). https://doi.org/10.1007/s11071-015-2040-2

14. Roberts, M.G., Heesterbeek, J.A.P.: Characterizing the next-generation matrix and basic reproduction number in ecological epidemiology. J. Math. Biol. 66, 1045-1064 (2013). https://doi.org/10.1007/s00285-012-0602-1

15. Biswas, S., Samanta, S., Khan, Q.J.A., Chattopadhyay, J.: Effect of multiple delays on the dynamics of cannibalistic prey-predator system with disease in both populations. Int. J. Biomath. 10, Article ID 1750049 (2017). https://doi.org/10.1142/S1793524517500498

16. Freedman, H.I., Wolkowicz, G.S.K.: Predator-prey systems with group defence: the paradox of enrichment revisited. Bull. Math. Biol. 48, 493-508 (1986). https://doi.org/10.1007/BF02462320

17. Xiao, D.M., Li, W.X., Han, M.A.: Dynamics in a ratio-dependent predator-prey model with predator harvesting. J. Math. Anal. Appl. 324, 14-29 (2006). https://doi.org/10.1016/j.jmaa.2005.11.048

18. Kar, T.K., Ghosh, B.: Sustainability and optimal control of an exploited prey predator system through provision of alternative food to predator. Biosystems 109, 220-232 (2012). https://doi.org/10.1016/j.biosystems.2012.02.003

19. Das, T., Mukherjee, R.N., Chaudhuri, K.S.: Harvesting of a prey-predator fishery in the presence of toxicity. Appl. Math. Model. 33, 2282-2292 (2009). https://doi.org/10.1016/j.apm.2008.06.008

20. Liu, X.X., Huang, Q.D.: The dynamics of a harvested predator-prey system with Holling type IV functional response. Biosystems 169-170, 26-39 (2018). https://doi.org/10.1016/j.biosystems.2018.05.005

21. Li, M., Chen, B.S., Ye, H.W.: A bioeconomic differential algebraic predator-prey model with nonlinear prey harvesting. Appl. Math. Model. 42, 17-28 (2017). https://doi.org/10.1016/j.apm.2016.09.029

22. Xiao, D.M., Jennings, L.S.: Bifurcations of a ratio-dependent predator-prey system with constant rate harvesting. SIAM J. Appl. Math. 65, 737-753 (2006). https://doi.org/10.1137/S0036139903428719

23. LV, Y.F., Zhang, Z.Y., Yuan, R., Pei, Y.Z.: Effect of harvesting and prey refuge in a prey-predator system. J. Biol. Syst. 22, 133-150 (2014). https://doi.org/10.1142/S0218339014500089

24. De Tao, Y., Wang, X., Song, X.Y.: Effect of prey refuge on a harvested predator-prey model with generalized functional response. Commun. Nonlinear Sci. Numer. Simul. 16, 1052-1059 (2011). https://doi.org/10.1016/j.cnsns.2010.05.026

25. Kar, T.K.: Stability analysis of a prey-predator model incorporating a prey refuge. Commun. Nonlinear Sci. Numer. Simul. 10, 681-691 (2005). https://doi.org/10.1016/j.cnsns.2003.08.006

26. Ma, Z.H., Wang, S.F., De Li, W., Li, Z.Z.: The effect of prey refuge in a patchy predator-prey system. Math. Biosci. 243 126-130 (2013). https://doi.org/10.1016/j.mbs.2013.02.011

27. Kar, T.K., Chaudhuri, K.S.: Harvesting in a two-prey one-predator fishery: a bioeconomic model. ANZIAM J. 45 , 443-456 (2004). https://doi.org/10.1017/S144618110001347X

28. Takashina, N., Mougi, A., Iwasa, Y.: Paradox of marine protected areas: suppression of fishing may cause species loss. Popul. Ecol. 54, 475-485 (2012). https://doi.org/10.1007/s10144-012-0323-8

29. Ghosh, B., Kar, T.K.: Possible ecosystem impacts of applying maximum sustainable yield policy in food chain models. J. Theor. Biol. 329, 6-14 (2013). https://doi.org/10.1016/j.jtbi.2013.03.014

30. Legović, T.: Impact of demersal fishery and evidence of the Volterra principle to the extreme in the Adriatic sea. Ecol. Model. 212, 68-73 (2008). https://doi.org/10.1016/j.ecolmodel.2007.10.014

31. Guin, L.N., Acharya, S.: Dynamic behaviour of a reaction-diffusion predator-prey model with both refuge and harvesting. Nonlinear Dyn. 88, 1501-1533 (2017). https://doi.org/10.1007/s11071-016-3326-8

32. Clark, C.W.: Mathematical Bioeconomics: The Optimal Management of Renewable Resources. Wiley-Interscience, New York (1976)

33. Perko, L.: Differential Equations and Dynamical Systems, 3rd edn. Springer, New York (2001)

34. Hale, J.K.: Ordinary Differential Equations, 2nd edn. Wiley, New York (1969)

35. Tripathi, J.P., Abbas, S., Thakur, M.: Local and global stability analysis of a two prey one predator model with help. Commun. Nonlinear Sci. Numer. Simul. 19, 3284-3297 (2014). https://doi.org/10.1016/j.cnsns.2014.02.003

36. Chen, F., Ma, Z.Z., Zhang, H.Y.: Global asymptotical stability of the positive equilibrium of the Lotka-Volterra prey-predator model incorporating a constant number of prey refuges. Nonlinear Anal., Real World Appl. 13, 2790-2793 (2012). https://doi.org/10.1016/j.nonrwa.2012.04.006

37. Paul, P., Kar, T.K., Ghorai, A.: Impact of marine reserve on maximum sustainable yield in a traditional prey-predator system. Commun. Nonlinear Sci. Numer. Simul. 54, 34-49 (2018). https://doi.org/10.1016/j.cnsns.2017.05.013

38. Gupta, R.P., Banerjee, M., Chandra, P.: Period doubling cascades of prey-predator model with nonlinear harvesting and control of over exploitation through taxation. Commun. Nonlinear Sci. Numer. Simul. 19, 2382-2405 (2014). https://doi.org/10.1016/j.cnsns.2013.10.033 
39. Nie, L.F., Teng, Z.D., Hu, L., Peng, J.G.: The dynamics of a Lotka-Volterra predator-prey model with state dependent impulsive harvest for predator. Biosystems 98, 67-72 (2009). https://doi.org/10.1016/j.biosystems.2009.06.001

40. Larkin, P.A.: An epitaph for the concept of the maximum sustained yield. Trans. Am. Fish. Soc. 106, 1-11 (1977). https://doi.org/10.1577/1548-8659(1977)106<1:AEFTCO>2.0.CO;2

41. Ghosh, B., Kar, T.K., Legović, T.: Sustainability of exploited ecologically interdependent species. Popul. Ecol. 56, 527-537 (2014). https://doi.org/10.1007/s10144-014-0436-3

42. Teo, K.L., Goh, C.J., Wong, K.H.: A Unified Computational Approach to Optimal Control Problems. Longman, New York (1991)

43. Yang, F., Teo, K.L., Loxton, R., Rehbock, V., Li, B., Yu, C.J., Jennings, L.: VISUAL MISER: an efficient user-friendly visual program for solving optimal control problems. J. Ind. Manag. Optim. 33, 2282-2292 (2009). https://doi.org/10.3934/jimo.2016.12.781

44. Leopold, A.: Game Management. University of Wisconsin Press, Madison (1986)

45. Sinclair, A.R.E., Fryxell, J.M., Caughley, G.: Wildlife Ecology, Conservation, and Management, 2nd edn. Wiley, Malden (2006)

46. Washenberger, M.J., Mobilia, M., Täuber, U.C.: Influence of local carrying capacity restrictions on stochastic predator-prey models. J. Phys. Condens. Matter 19, 65-139 (2007). https://doi.org/10.1088/0953-8984/19/6/065139

47. Hayward, M.W., O'Brien, J., Kerley, G.I.H.: Carrying capacity of large African predators: predictions and tests. Biol. Conserv. 139, 219-229 (2007). https://doi.org/10.1016/j.biocon.2007.06.018

\section{Submit your manuscript to a SpringerOpen ${ }^{\circ}$ journal and benefit from:}

- Convenient online submission

- Rigorous peer review

Open access: articles freely available online

- High visibility within the field

- Retaining the copyright to your article

Submit your next manuscript at $\boldsymbol{~ s p r i n g e r o p e n . c o m ~}$ 